\title{
Informational Lobbying under the Shadow of Political Pressure ${ }^{\star}$
}

\author{
Matthias Dahm*,a \\ a CMS-EMS (Center for Mathematical Studies in Economics and Management \\ Science), Northwestern University, 2001 Sheridan Rd, Evanston, IL 60208, USA. \\ Nicolás Porteiro ${ }^{b}$ \\ b Dpto. Economía, Met. Cuantitativos e Hist. Económica. Universidad Pablo de \\ Olavide. Carretera de Utrera km. 1. Sevilla 41013 (Spain).
}

\begin{abstract}
We examine the incentives of an interest group to provide verifiable policy-relevant information to a political decision-maker and to exert political pressure on her. We show that both lobbying instruments are interdependent. In our view information provision is a risky attempt to affect the politician's beliefs about the desirability of the lobby's objective. The constraints governing informational lobbying determine a specific lottery available. The circumstances under which political pressure can be applied specify the lobby's valuation of different beliefs of the politician and, thus, her attitude toward risk. The combination of lotteries available and induced risk preference determines the optimal lobbying behavior.

Our approach gives a novel explanation for the fact that interest groups often try to provide information credibly. We identify several factors that induce risk proclivity (and thus information provision). We also show that the availability of political pressure might have a deterrence effect on information provision. This 'shadow of political pressure' might impede information provision at all or induce a complementary relationship between both lobbying instruments.
\end{abstract}

JEL Classification: C72; D72.

Keywords: Experts, Influence, Credibility, Political contributions, Issue ads.

^ This version: 18 July 2005.

* Corresponding author. Email: m-dahm@kellogg.northwestern.edu. 


\section{Introduction}

In the United States the Food and Drug Administration (FDA) has an elaborate clinical trial process that requires specific information from pharmaceutical companies when examining new drugs for distribution to the public. ${ }^{1}$ In a joint editorial published in September 2004, The International Committee of Medical Journal Editors (ICMJE) stated that greater openness is needed to prevent clinical trials information from being selectively reported. ${ }^{2}$ However, information is not always hold back. An example is a study sponsored by Bristol-Myers Sqibb and carried out at Harvard University's medical complex. The study compared the performance of two prescription drugs and concluded, contrary to Bristol Myers Sqibb's interest, that the sponsor's drug was not as effective as the competitor's. ${ }^{3}$ In addition to the strategic provision of information, drug companies are believed to have other means to influence the FDA approval process. For instance, two strategies are reported to be now widely adopted: "(1) Firms themselves have in the past six to eight years created, fostered, and subsidized a number of patient advocacy groups; and (2) firms regularly seek alliances with patient advocates in pressing the case for priority status, accelerated approval, or simply approval before the FDA". ${ }^{4}$

Casual observations like the preceding raise questions. When is verifiable information voluntarily provided? Suppose there is an institutional arrangement that allows information providers to commit not to hold back information once they have learned evidence that harms their cause. What are the incentives to use such a commitment device? Is there a relationship between the incentives to provide information voluntarily and the incentives to use these commitment devices? How does the availability of other means of influence affect the incentives for information provision? More broadly, why do lobbies usually engage in both informational lobbying and other means of influence, say campaign contributions?

To provide some answers to these questions we model a political decisionmaker who has to take a single policy decision and is lobbied by an interest group. ${ }^{5}$ The politician is both responsive to political pressure and wants to

1 It demands pre-clinical testing and approves the clinical trial protocols. The FDA can refuse to file an application that is incomplete because, for example, some required studies are missing. See e.g. Meadows (2002).

2 The 11 journals - which include prestigious institutions such as the New England Journal of Medicine - agreed officially not to publish studies in their respective journals which contain references to clinical trials that have not been registered publicly, see ICMJE (2004).

3 See Cannon et al (2004).

4 See Carpenter (2004), p. 56.

5 Throughout this paper we use the words "political decision-maker", "politi- 
make 'good' decisions. ${ }^{6}$ In her decision she trades off 'acting optimally given her beliefs about the suitability of each policy' against the pressure of the lobby. The more 'convinced' she is that the group's objective is a 'good' policy, the easier for the lobby to influence her through pressure. Before deciding on political pressure the lobby can invest in costly policy relevant information with the hope to affect the politician's beliefs in such a way that she is more likely to decide in favor of the group. However, informational lobbying may be unsuccessful and as a result the politician is more convinced not to support the lobby's cause. This structure implies that informational lobbying has a strategic effect on the pressure game. If informational lobbying is successful, this effect is positive. If it is not, the effect is negative.

The main point to take away from the present paper is that there is an important strategic interaction between both lobbying instruments. Information provision is a risky attempt to affect the politician's beliefs about the desirability of the lobby's objective. The constraints governing informational lobbying determine a specific lottery available. The circumstances under which political pressure can be applied define the manner in which the lobby's payoffs in the pressure game respond to different beliefs of the politician. This specifies the lobby's valuation of different beliefs of the politician and, thus, her attitude toward risk. The combination of lotteries available and induced risk preference determines the optimal lobbying behavior.

The first part of this paper analyzes the importance of the induced risk preference for informational lobbying in an abstract continuation game. The continuation games considered embody different reasonable - but benchmark responses to beliefs of the politician. An advantage of our focus on these responses is to allow the derivation of results that do not depend on the politician's prior belief. So, Section 2 outlines a model of informational lobbying without specifying the continuation game in detail. Following Milgrom (1981), we analyze informational lobbying in terms of verifiable reports rather than the alternative 'cheap talk' framework of Crawford and Sobel (1982). ${ }^{7}$

cian" and "legislator", on one hand and on the other "interest group", "group" and "lobby" interchangeably. Also, we employ the words "to lobby" and "to influence" when referring to both activities of a lobby.

6 We employ an abstract notion of political pressure intended to capture campaign contributions, bribes, issue adds, endorsement of candidates or propaganda campaigns like May Day marches. Propaganda campaigns make the electorate more sensitive to the issues that matter for the lobby. An example is the effort of the association of chemists in Germany or Spain to maintain a situation in which (even nonprescription) drugs can only be sold in drugstores. The message of these campaigns is that at a chemist's shop one gets not only medicines but also advice.

7 Apart from the example of drug approval Wright (1996, p. 112) lends support to our modelling choice: "The ability of legislators to at least occasionally verify lobbying information is a crucial part of the lobbying process". 
This permits us, on one hand, to argue that the constraints of informational lobbying determine a specific lottery available.

On the other, it enables us to address in Section 3 the issue of credibility of informational lobbying that the descriptive literature on lobbying has identified to be an important concern of lobbies. We specify two simple benchmark information transmission technologies that can be interpreted as commissioning external experts (we call this a public test) or a lobby doing the research on its own (we call this a private test). We argue that both technologies resolve the trade-off between credibility and scope for manipulation differently. While the external expert is perfectly credible because he always reveals what he has learned, a lobby doing research by himself can hold back information. ${ }^{8}$

In our model credible information provision is a natural lobbying behavior because the incentives to provide information voluntarily are linked to a preference to commit not to hold back information in order to increase the lobby's credibility. The link we provide is that both a commitment not to hold back information and providing information per se are risky activities. Hence, both choices depend in the same way on the lobby's disposition to accept risk. When should we then expect risk proclivity (and thus information provision)?

In order to answer this question we specify in Section 4 several specific pressure games. Although the details of the optimal lobbying behavior are sensible to different model specifications, our analysis yields some key findings:

(1) As predicted in Section 3, if informational lobbying takes place, the lobby prefers to do so credibly. (Virtually true for all models in Section 4.)

(2) If applying pressure is straightforward, then the lobby is risk averse and both instruments are not employed together. Informational lobbying is only an option if political pressure is too expensive. Under the assumption of a private test this is the result of Bennedsen and Feldmann (2005), but it also holds to a large extent for the other test. (Subsection 4.1)

(3) When we move away from this benchmark, informational lobbying becomes relatively more profitable and the lobby accepts more risk. This holds for both tests and explains the empirical finding that lobbies use both informational lobbying and political pressure together (see e.g. Wright (1990)). (Subsections 4.2 and 4.3)

(4) The availability of political pressure might have a deterrence effect on information provision. If the incentives for risk taking are low, the deterrence effect might impede information provision at all, while for more risk

8 Schlozman and Tierney (1986, p. 103) report that a "reputation for being credible and trustworthy is especially critical for those organizations whose representatives have direct contact with government officials". Berry (1997, p. 98) summarizes "credibility comes first". Wright (1996, p. 3) reports that lobbies frequently use external experts and that they also often do research on their own. 
proclivity, the deterrence effect might result in a complementary relationship between the pressure exerted and the level of information provided. ${ }^{9}$ This, again, is true for both tests. (Subsections 4.2 and 4.3)

(5) For given costs of pressure, that is, a given attitude toward risk, lobbying behavior depends also on the characteristics of the information game, that is, the specific lottery available. (Subsections 4.1 and 4.2)

Despite the fact that there is a literature analyzing how lobbies influence political decisions by, on one hand, political pressure and, on the other hand, providing policy-relevant information, little is known about the interaction of both lobbying instruments. ${ }^{10}$ Previous to us - but in independent work - Bennedsen and Feldmann (2005) analyze a closely related model. We have already related their work to our key findings and explain further connections at the appropriate place in the analysis. Our companion paper Dahm and Porteiro (2005) builds on the results derived in the present paper (particularly (4) above) and explores policy implications for campaign finance reform.

We are not aware of other works in which political pressure and informational lobbying interact as in the present paper. ${ }^{11}$ In Austen-Smith (1995 and 1998) and Lohmann (1995a) contributions are necessary in order to gain access to a political decision-maker. Without access the lobby cannot transmit information and can therefore not advance his issues. Such a setting is different from our approach in which political pressure may directly induce the lobby's preferred outcome. We provide therefore a different explanation why both lobbying instruments might be used together. The work of Yu (2005) is related, because it analyzes the choice of interest groups between different lobbying instruments (lobbying the government or persuading the public).

$\overline{9}$ To be precise, we say that this relationship is complementary if an increase in the marginal costs of pressure results in a lower level of both informational lobbying and political pressure. If the former is increased while the latter is reduced, we say that the instruments are substitutes.

10 Reviews of both strands of literature can be found in Austen-Smith (1997) or Grossmann and Helpman (2001).

11 For instance Sloof and van Winden (2000) analyze the decision of a lobby between persuasion through the use of 'words' or 'actions' in a repeated signaling game. The driving force is the reputation of the lobby that determines if a threat is enough to persuade or must be carried out. Therefore, its focus lies in what we consider to be 'political pressure'. Lohmann (1995b) develops a signaling model of competitive political pressures as collective actions. In her model pressure plays a purely informational role because it helps a decision-maker to extract information about the state of the world. 


\section{A Simple Model of Verifiable Informational Lobbying}

There are two states of the world $a$ and $b$. The true state of the world $\omega$ is unknown, but it is common knowledge that the probability of state $a$ is $q_{0}<1$. A political decision-maker $D M$ has to decide between two policies $A$ and $B$, the idea being that policy $A$ is correct in state $a$ and $B$ in the other. On one hand, the politician wants to make 'good' decisions and is more inclined to choose $A$ the higher her prior belief $q_{0}$. On the other, she is responsive to political pressure of a lobby preferring policy $B$ independent of the state $\omega$.

Consider a sequential game with the following decision stages:

(1) $L$ may engage in informational lobbying summarized in a variable $x$.

(2) Taking into account informational lobbying, $D M$ updates rationally her beliefs over the likelihood of each state of the world to $q_{x}$.

(3) $L$ decides how much pressure to exert given $q_{x}$.

(4) $D M$ decides over the policy, given $q_{x}$ and the political pressure of $L$.

This game can be solved by backwards induction: given the result of informational lobbying, that is, a posterior belief $q_{x}$ of the politician, the group acts optimally in the pressure game. A higher $q_{x}$ corresponds to a lower payoff in the pressure game because the politician is more convinced that the lobby's aim is the 'wrong' policy and more pressure is needed. In Section 3 we focus on a (decreasing) payoff function $E \Pi_{L}(q)$ representing the later decision stages. We relate the shape of this function to the incentives for informational provision. ${ }^{12}$ We describe now a simple model of informational lobbying.

The interest group may acquire costly policy-relevant information and decide whether to transmit it. When the agenda is announced, $L$ is supposed to have no more information than $D M$. The lobby chooses between the following two instruments of informational lobbying.

Private test $[\mathrm{PR}]$ : At a cost $C(x)$ the lobby can buy a test which reveals with probability $x \in[0,1]$ the true state of the world, that is, $t=\omega$. With probability $1-x$ the test is not successful, no information is obtained and $t=\emptyset$. The result of the test is hard evidence and the investment in information $x$ is observed by the politician. Once the test is carried out the interest group

\footnotetext{
$\overline{12}$ In Section 4 we assume more structure on the pressure game. However, as we will see shortly, apart from political pressure there are other continuation games that provide a micro-foundation for $E \Pi_{L}(q)$ and to which our results also apply. It is intuitive that the lobby prefers the decision sequence outlined to both a simultaneous decision and the sequence pressure-information. The reason is that it allows the group to adjust the pressure activity to the outcome of the informational lobbying stage.
} 
decides on what kind of message $M$ to send to $D M$. The lobby may hold back information but cannot lie and convince the politician. Thus, if $t=\omega$, then $M \in\{\omega, \emptyset\}$ and if $t=\emptyset$, then $M=\emptyset$. The underlying idea of a private test is that the interest group can carry out some research and then decide strategically how to use this information. If the state is $a$, the lobby does not need to reveal this information. This strategic scope limits the credibility of the message that the test failed. ${ }^{13}$

Public test [PU]: At the same cost $C(x)$, the lobby can buy another test which has exactly the same properties as a private test. It differs only in the set of admissible messages. Under a public test the test result is always revealed $(M=t)$. A public test captures the idea of an external expert paid by the lobby who always reveals all that he knows. Once the test is carried out, there is no strategic scope but the message that the test has failed is credible. On the other hand, if the state is $a$, this will be revealed.

\section{How the Attitude Toward Risk Affects Informational Lobbying}

\subsection{Credibility versus Scope for Manipulation}

In this subsection we analyze the determinants of the test choice of the lobby. We focus on any level $x \in(0,1)$ of informational lobbying and provide a 'dominance-type of result' concerning the optimal test choice. Since both tests are assumed to cause the same costs, in this section the cost function $C(x)$ plays no role. Also, the level $x$ considered may be the lobby's optimal choice or a level induced by some type of formal or informal constraint. ${ }^{14}$

From the outset it is not clear which test is more advantageous for the group. With probability $x\left(1-q_{0}\right)$ informational lobbying has a positive effect $(t=b)$

$\overline{13}$ Wright (1996) reports (on page 4) that even “... today the prevailing assumption among interest group scholars is that lobbyists may shade the truth from time to time, but they do not deliberately distort it for their own advantage". Modelling the strategic discretion of an economic agent by what we call a private test is widely used, see Laffont (1999). It was introduced in the literature on informational lobbying by Bennedsen and Feldmann (2002 and 2005). See also Aghion and Tirole (1997) and specially Chapter 11 in Laffont and Tirole (1993).

14 The FDA regulations mentioned provide one example for compulsory information provision. Another example in which a minimal level of information provision might be required is that lobbies need to be perceived 'as a player in Washington politics' (see Wright (1996, p. 76). The literature often assumes that informational lobbying is either done or not and if it is done it reveals the true state with some fixed probability. This is equivalent to buying a fixed amount of information or not. 
Table 1

Effect of Informational Lobbying on the Politician's Belief

\begin{tabular}{|l|c|c|c|}
\hline test result & $t=b$ & $t=a$ & $t=\emptyset$ \\
\hline probability of $t$ & $x\left(1-q_{0}\right)$ & $x q_{0}$ & $1-x$ \\
\hline$q_{x}$ with public test & 0 & 1 & $q_{0}$ \\
\hline$q_{x}$ with private test & 0 & $q(x)$ & $q(x)$ \\
\hline
\end{tabular}

and both tests induce the same posterior $q_{x}=0$. However, with the remaining probability the negative effect occurs and differs under both tests.

With a public test the politician updates with probability $x q_{0}$ to $q_{x}=1$ (because $t=a$ ) and with probability $1-x$ to $q_{x}=q_{0}$ (when $t=\emptyset$ ). When the private test is successful and the state is not the ideal one for the interest group $(t=a)$, the lobby prefers to hold back this information, because the lobby can do better than revealing the true state by sending the message that the test has failed $(M=\emptyset)$. Therefore, when receiving this message the politician knows that it is more likely than $q_{0}$ that the true state is $a$. Bayes' rule gives the posterior $q_{x}=q(x) \equiv \frac{q_{0}}{1-x\left(1-q_{0}\right)} \geq q_{0} .{ }^{15}$ Therefore, the negative strategic effect of a private test leads to an intermediate value $q(x) \in\left[q_{0}, 1\right]$. Table 1 gives a summary.

Ex-ante informational lobbying, the total expected profits of the lobby under both tests, private (PR) and public (PU), are given by

$$
\begin{aligned}
E \Pi_{L}^{P R}(x)= & x\left(1-q_{0}\right) E \Pi_{L}\left(q_{x}=0\right) \\
& +\left(1-x\left(1-q_{0}\right)\right) E \Pi_{L}\left(q_{x}=q(x)\right)-C(x) \\
E \Pi_{L}^{P U}(x)= & x\left(1-q_{0}\right) E \Pi_{L}\left(q_{x}=0\right) \\
& +x q_{0} E \Pi_{L}\left(q_{x}=1\right)+(1-x) E \Pi_{L}\left(q_{x}=q_{0}\right)-C(x) .
\end{aligned}
$$

Comparison of these expressions yields the intuitive insight that the lobby prefers the information technology that causes the less harmful negative effect. The next proposition links the test choice to the properties of the continuation

$\overline{15}$ Note that the higher the quality of the test, the higher the probability the politician assigns to state $a$ after receiving the message that the test has failed. Formally, $\frac{\partial q(x)}{\partial x}=\frac{\left(1-q_{0}\right) q_{0}}{\left[1-x\left(1-q_{0}\right)\right]^{2}}>0$. Moreover, $q(x=0)=q_{0}$ and $q(x=1)=1$. 
game. ${ }^{16}$ All proofs are relegated to an Appendix.

Proposition 3.1 For all $x \in(0,1)$ and for all $q_{0}$

(i) the private test is strictly preferred, if $E \Pi_{L}(q)$ is strictly concave;

(ii) the public test is strictly preferred, if $E \Pi_{L}(q)$ is strictly convex and

(iii) the lobby is indifferent between the tests, if $E \Pi_{L}(q)$ is linear.

To gain an intuition for the role the curvature of the profit function plays for the test choice, we draw an analogy to the basic theory of choice under uncertainty. In this analogy the function $E \Pi_{L}(q)$ takes on the role of the Bernoulli utility function and $q_{x}$ the one of income. Note that each test defines a lottery. Since both lotteries yield with probability $x\left(1-q_{0}\right)$ a payoff of $E \Pi_{L}\left(q_{x}=0\right)$, the lobby's preference is determined only by the comparison of the remaining events.

Under a public test $[\mathrm{PU}] q_{x}$ can be thought of as a random variable which can take on two values, $\left\{q_{0}, 1\right\}$. The probability of the first value is $\frac{1-x}{1-x\left(1-q_{0}\right)}$ while the one of the second is $\frac{x q_{0}}{1-x\left(1-q_{0}\right)}$. Consequently, the expected outcome is $\frac{1-x}{1-x\left(1-q_{0}\right)} q_{0}+\frac{x q_{0}}{1-x\left(1-q_{0}\right)}=q(x)$ which is shown in Figure 1 on the horizontal axis as the convex combination of $q_{0}$ and 1 . The public test for a given level of information $x$ is then represented by the chord connecting $\left(q_{0}, E \Pi_{L}\left(q_{0}\right)\right)$ and $\left(1, E \Pi_{L}(1)\right)$ with expected utility $E \Pi_{L}(P U)=\frac{1-x}{1-x\left(1-q_{0}\right)} E \Pi_{L}\left(q_{x}=q_{0}\right)+$ $\frac{x q_{0}}{1-x\left(1-q_{0}\right)} E \Pi_{L}\left(q_{x}=1\right)$.

The private test $[\mathrm{PR}]$ can be thought of as the degenerate lottery that pays $q(x)$ with certainty, that is, $E \Pi_{L}(P R)=E \Pi_{L}(q(x))$. Concavity of $E \Pi_{L}(q)$ implies that $E \Pi_{L}(P R)>E \Pi_{L}(P U)$ and, therefore, induces the lobby to behave as risk averse and to prefer the private test. ${ }^{17}$

Although the case depicted in Figure 2 does not fit exactly into the categories of Proposition 3.1, the main intuition can be applied. The public test is represented by the chord connecting $\left(q_{0}, E \Pi_{L}\left(q_{0}\right)\right)$ and $\left(1, E \Pi_{L}(1)\right)$. We have that $E \Pi_{L}(P R)<E \Pi_{L}(P U)$. For the relevant values of $q_{0}$ and $q(x)$, the lobby exhibits risk proclivity, even though $E \Pi_{L}(q)$ is strictly concave for some $q .{ }^{18}$ We present now examples in order to show that the benchmark cases of Proposi-

\footnotetext{
$\overline{16}$ As mentioned before Wright (1996) reports that lobbies frequently use external experts and that they also often do research own their own. The next proposition provides therefore a rationale of when we should observe each choice.

17 We could also define a certainty-equivalent allocation $q_{c}$ which the lobby considers to be equally advantageous as the public test. Of course, because the lobby prefers a lower $q$, we have $q(x)<q_{c}$.

18 In the remainder of the sequel we will use the simplifying language of risk aversion and risk proclivity without adding the qualification "for the relevant values of $q_{0}$ and $q(x) "$. In Subsection 4.1 we provide a micro-foundation for Figure 2.
} 


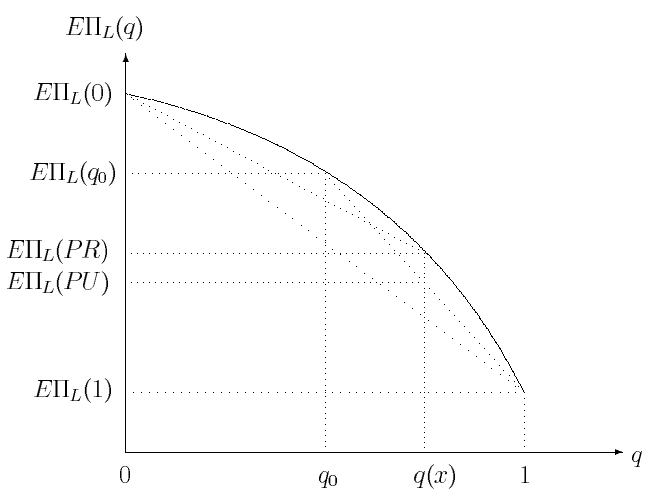

Fig. 1. An Example of Risk Aversion

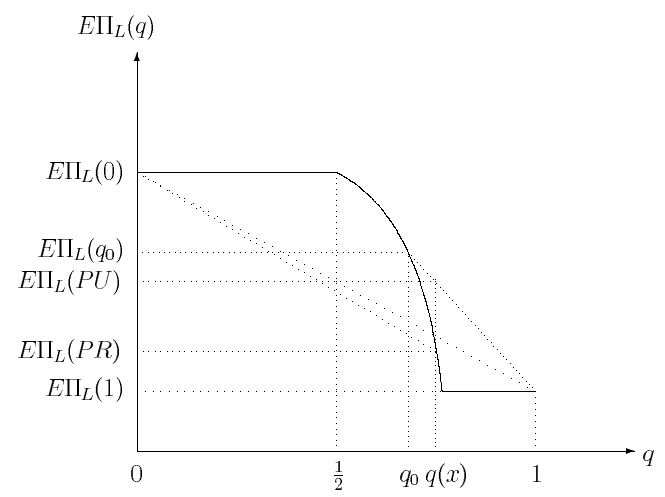

Fig. 2. An Example of Risk Proclivity

tion 3.1 may arise naturally. ${ }^{19}$

Example 3.1 [Disclosures and asset returns à la Shin (2003)].

A firm undertakes a project which succeeds with probability $1-q_{0}$ and fails with probability $q_{0}$. If the project is a success the liquidation value of the firm is $u$ and $d$ otherwise, where $0<d<u$. The manager is interested in maximizing the price of the firm. The market fixes the price based on all available evidence. Before the project is terminated and its result is publicly observed there is an interim stage in which the manager has observed with probability $x$ the success of the project. At this date the manager decides on a disclosure policy in order to maximize the interim value of the firm. In this example $E \Pi_{L}(q)=$ $q d+(1-q) u$. Since this is a linear function, the manager acts as risk neutral and is indifferent between both tests.

Example 3.2 [Pork barrel projects à la Bennedsen and Feldmann (2002)]. There is a legislature composed of three districts (indexed by $i$ ) that decides on the aggregate level $G$ of a public good and to what extent $g_{i}$ each district $i$ benefits from it $\left(\Sigma_{i=1}^{3} g_{i}=G\right)$. Due to equal sharing of provision costs among the three districts, each legislator maximizes $u_{i}=r_{i} g_{i}-\frac{1}{6} G^{2}$, where the marginal valuations $r_{i} \in\{0,1\}$ differ across districts. The uncorrelated $r_{i}$ 's are equal to one with probability $1-q_{0}$. Legislators form a policy coalition in order to pass by majority voting a bill proposed by a randomly chosen agenda setter.

An interest group can promote the provision of the public good through informational lobbying. Before the agenda setter is determined the group must search in exactly one (randomly determined) district. The level of informational lobbying $x \in(0,1)$ is fixed. After receiving the lobby's message the agenda setter chooses the allocation of the public good so as to maximize his own (expected) payoff, subject to receiving the support of one other legislator.

19 The examples are simplified instances in which the literature uses a private test. A second purpose we pursue by choosing these examples is to show that Proposition 3.1 is meaningful in a much wider class of situations than the ones involving a continuation game in which political pressure is available. 
The legislator outside the policy coalition does not receive benefits from the public good but contributes to its cost.

Incentives for informational lobbying are given by the total amount of the public good provided $E \Pi_{L}(q)=G^{*}(q)=\frac{3}{\frac{1}{1-q}+B}$ otherwise, where $B$ is a positive constant. Since this is a strictly concave function, risk aversion is induced and the lobby prefers strictly the private test. ${ }^{20}$

In our companion paper Dahm and Porteiro (2005) we analyze a lobbying model in which $E \Pi_{L}(q)$ is strictly convex. Another instance in which $E \Pi_{L}(q)$ is strictly convex is given by Example 3.2 when the lobby is an environmental group that is interested in minimizing the total amount of the public good, say local highway constructions. ${ }^{21}$

\subsection{Voluntary Information Provision}

In this subsection we analyze when the lobby voluntarily engages in informational lobbying. As in the last subsection we work with $E \Pi_{L}(q)$ which is now assumed to be continuously differentiable. For clarity of the exposition we suppose also that the cost function $C(x)$ is increasing and strictly convex, and subject to the usual boundary condition that $C^{\prime}(0)=0 .{ }^{22}$

Proposition 3.2 Under both tests and for all $q_{0}$ the following is true

(i) there is informational lobbying, if $E \Pi_{L}(q)$ is strictly convex and

(ii) there is no informational lobbying, if $E \Pi_{L}(q)$ is concave.

Again, we gain an intuition from an analogy to the basic theory of choice under uncertainty. Informational lobbying can be thought of as a lottery between two values, while not engaging in informational lobbying yields a certain amount with certainty. A lobby only engages in information provision if the continuation game induces risk proclivity. If risk aversion is induced, no information

$\overline{20}$ To be fully precise, this example is not a special case of Proposition 3.1, because the objective functions at the informational lobbying stage are slightly different from equations (1) and (2). The reason is that the negative strategic effect of informational lobbying is mitigated by excluding the searched district from the policy coalition (when it does not coincide with the agenda setter). Since this possibility does not depend on the type of the test, it is straightforward to take this into account. Further details are available upon request (and for the convenience of the referees included in Appendix B.1 not intended for publication).

21 Interestingly, this implies that the incentives for informational lobbying may depend on which side of an issue a lobby is on.

22 If $E \Pi_{L}(q)$ is concave but not a straight line, Proposition 3.2 (ii) is true even if information is costless for the lobby. 
is provided - even if information is costless for the group. ${ }^{23}$

Propositions 3.1 and 3.2 link the incentives for engagement in informational lobbying to those for a commitment to provide credible information, because both depend in the same way on the lobby's attitude toward risk.

Corollary 3.1 Suppose information is voluntarily provided. Then for all $q_{0}$ (i) there is informational lobbying and the public test is strictly preferred, if $E \Pi_{L}(q)$ is strictly convex;

(ii) there is no informational lobbying (and no negative strategic effect) so that the lobby is trivially indifferent among the tests, if $E \Pi_{L}(q)$ is concave.

Although the situations considered in the next section are not a special case of this Corollary, it provides strong intuitions for the results because the same forces are at play.

\section{How the Pressure Game Affects the Attitude Toward Risk}

We analyze now a series of related examples which provide micro-foundations for specific formulations of the function $E \Pi_{L}(q)$ and support for the key findings laid out in the Introduction.

$\overline{23}$ This argument can be made precise (see also Figure 1). A private test yields $q_{x} \in\{0, q(x)\}$. The expected outcome is $q_{0}$. Thus, the relevant comparison is $E \Pi_{L}\left(q_{x}=q_{0}\right) \lesseqgtr E \Pi_{L}^{P R}(x)=x\left(1-q_{0}\right) E \Pi_{L}\left(q_{x}=0\right)+\left(1-x\left(1-q_{0}\right)\right) E \Pi_{L}\left(q_{x}=q(x)\right)$. A public test differs from the degenerate lottery only if the test is successful. Conditional on success it yields $q_{x} \in\{0,1\}$ with expected outcome $q(x)$. The comparison is $E \Pi_{L}\left(q_{x}=q(x)\right)$ (or $E \Pi_{L}(P R)$ in Figure 1) with $E \Pi_{L}^{P U}(x)=\frac{x\left(1-q_{0}\right)}{1-x\left(1-q_{0}\right)} E \Pi_{L}\left(q_{x}=\right.$ $0)+\frac{x q_{0}}{1-x\left(1-q_{0}\right)} E \Pi_{L}\left(q_{x}=1\right)$. The reader familiar with Bennedsen and Feldmann (2002) might have noticed that, although in their paper $E \Pi_{L}(q)$ is concave, sometimes information is provided. The reason is as follows. When the legislature has a single member (their Lemma 2), $E \Pi_{L}(q)=1-q$ is linear and Proposition 3.2 (ii) applies. For larger legislatures, $E \Pi_{L}(q)$ is strictly concave, but, as pointed out in footnote 20, our benchmark is distorted because the negative strategic effect of informational lobbying is lowered by excluding the searched district from the policy coalition. This increases the expected value of the private test, resulting in informational lobbying when the legislature is large enough (their Proposition 2). Thus, Proposition 3.2 provides a benchmark result that helps to understand different institutional environments of informational lobbying. 


\subsection{A Benchmark: Information under the Shadow of Pressure}

\subsubsection{The Benchmark Model of Information and Pressure}

Suppose the politician obtains $R_{h}$ if state and policy are matched correctly and $R_{l}$ otherwise. We normalize to $R_{h}-R_{l} \equiv R \in(0,1]$ and suppose that $q_{0} \in\left(\frac{1}{2}, 1\right)$. Comparing the expected payoffs $E \Pi_{D M}(A)$ and $E \Pi_{D M}(B)$ of the politician from both policies we obtain that she chooses decision $A$, because

$$
\begin{aligned}
E \Pi_{D M}(A)-E \Pi_{D M}(B) & =q_{0} R_{h}+\left(1-q_{0}\right) R_{l}-q_{0} R_{l}-\left(1-q_{0}\right) R_{h} \\
& =\left(2 q_{0}-1\right) R \equiv \tilde{p}\left(q_{0}, R\right)>0 .
\end{aligned}
$$

The payoffs of the interest group $L$ from each policy are given by $\Pi_{L}(B)=V_{B}$ and $\Pi_{L}(A)=V_{A}$, with $V_{B}-V_{A} \equiv \Delta>0$. There is a conflict of interest and the lobby has incentives to influence the politician. To allow the derivation of closed form solutions, we assume from now on that the cost function of informational lobbying is $C(x)=k_{i} x^{2}$, where $k_{i}$ is a positive constant.

The lobby can also exert political pressure $p \in \mathbb{R}_{+}$on the politician at a cost $C(p)=k_{p} p^{2}$, where $k_{p}$ is a positive constant. ${ }^{24}$ We suppose that the politician compares her expected payoff premium, awarded by the electorate in the absence of any lobbying influence, from choosing policy $A$ to the pressure exerted. Formally, for any $q_{0}$ and $R$, the politician chooses policy $B$ if and only if $p \geq \tilde{p}\left(q_{0}, R\right)$. If either the stakes $R$ or the likelihood that the true state is $a$ increase, more pressure is required to induce policy $B .{ }^{25}$

${ }^{24}$ We choose the quadratic cost function mainly to be consistent with the information game. Postulating linear costs affects only the complementarity established in Proposition 4.5. However, this result could be restored by a minor change in the set-up (see Dahm and Porteiro (2005)).

25 This is in line with the literature e.g. in Snyder (1991) the more salient an issue is for politicians, the more costly it is to exert pressure successfully. We suppose here for simplicity that when indifferent $D M$ chooses $B$. Our simple additive form of the effect of political pressure has a relationship to the standard all-pay auction frequently employed to model campaign contributions (see e.g. Baye et al (1993), Che and Gale (1998) or Matějka et al (2002)). In an all-pay auction only the payments matter to the politician. This corresponds to the cases in which $R=0$ or $q_{0}=\frac{1}{2}$. Our formulation is more realistic because the politician also wants to take the 'right' decision. Moreover, such an incentive is needed for informational lobbying to play a role. As in virtually all models of political pressure we suppose that there is an implicit contract which solves the commitment problem. 


\subsubsection{Political Pressure in the Benchmark Game}

We use the notation $p_{M}^{*}$ to indicate the optimal pressure level following message $M$. Since $p_{b}^{*}=0$, we simplify notation and use $p^{*}$ to indicate $p_{M}^{*}, M \neq b$. To which test $p_{\emptyset}^{*}$ refers will be clear from the context.

Given any (posterior) belief $q_{x}>0$ the politician might hold in a pressure subgame, the group exerts the threshold level $p^{*}=\tilde{p}\left(q_{x}, R\right)$ whenever this is profitable, that is, $\frac{k_{p}}{\Delta} \leq \frac{1}{\tilde{p}\left(q_{x}, R\right)^{2}}$. In this case the payoffs are $E \Pi_{L}\left(q_{x}, R, p^{*}\right)=$ $V_{B}-k_{p} \tilde{p}\left(q_{x}, R\right)^{2}$. For higher costs, $p^{*}=0$ and $E \Pi_{L}\left(q_{x}, R, p^{*}\right)=V_{A}$.

This function $E \Pi_{L}\left(q_{x}, R, p^{*}\right)$ corresponds to $E \Pi_{L}(q)$ in the notation of the last section and is drawn in Figure 2. If the cost of pressure $\frac{k_{p}}{\Delta}$ are low, the pressure $p^{*}=\tilde{p}(1, R)=R$ associated with the highest possible belief is profitable. In this case the strictly concave part ends in the point $\left(1, E \Pi_{L}(1)\right)$ and the lower horizontal chord does not exist. However, as $\frac{k_{p}}{\Delta}$ increases, for high beliefs the necessary pressure level is no longer feasible. This creates the lower horizontal chord, because for high beliefs $E \Pi_{L}(1)=V_{A}$ is obtained. Therefore, as in the specific instance drawn, an increase in the cost of pressure induces risk proclivity. We analyze now in detail the incentives for voluntary information provision with each test and the induced preference over tests.

\subsubsection{A Private Test and Political Pressure in the Benchmark Game}

The negative strategic effect that informational lobbying can have on the pressure game leads to a posterior belief $q(x)$ resulting in a new threshold $\tilde{p}(q(x), R)$ which is increasing in the quantity of information bought. Informational lobbying may raise the cost of political pressure needed to induce the lobby's favorite outcome.

Bennedsen and Feldmann (2005) have shown that with a private test "interest groups may lack incentives to provide information if they have alternative ways to induce the decision-maker to choose the lobby's favored outcome." Although our model is different in some respects, an analogous result is true. Define $\tilde{x}=\min \left\{\frac{1-q_{0}}{2} \frac{\Delta}{k_{i}}, 1\right\}>0$.

Proposition 4.1 Under a private test the lobby does not use political pressure and informational lobbying together. There are two cases to be distinguished.

(i) For low $\frac{k_{p}}{\Delta}$ only political pressure is exerted: $x^{*}=0$ and $p^{*}=\tilde{p}\left(q_{0}, R\right)$.

(ii) For high $\frac{k_{p}}{\Delta}$ only informational lobbying is used: $x^{*}=\tilde{x}$ and $p^{*}=0$.

The definition of the threshold is in the Appendix. Figure 2 conveys the intuition. For low costs, the lower horizontal chord does not exist, risk aversion is induced and no informational lobbying takes place. For sufficiently high costs, 
the strictly concave part is 'pushed to the left,' risk proclivity is induced and information is provided. Both instruments are never combined because $p^{*}(q(x), R)>0$ requires $E \Pi_{L}(q(x))>V_{A}$. In this case the strictly concave part is 'not pushed enough to the left' to induce $x^{*}>0$ in the first place. ${ }^{26}$

\subsubsection{A Public Test and Political Pressure in the Benchmark Game}

The negative strategic effect that informational lobbying can have on the pressure game is different with a public test. The next result shows that this has consequences for the optimal lobbying behavior.

Proposition 4.2 Under a public test three cases must be distinguished.

(i) For low $\frac{k_{p}}{\Delta}$ only political pressure is exerted: $x^{*}=0$ and $p^{*}=\tilde{p}\left(q_{0}, R\right)$.

(ii) For intermediate $\frac{k_{p}}{\Delta}$ informational lobbying is combined with political pressure whenever the test fails: $0<x^{*}<\tilde{x}, p_{a}^{*}=0$ and $p_{\emptyset}^{*}=\tilde{p}\left(q_{0}, R\right)$.

(iii) For high $\frac{k_{p}}{\Delta}$ only informational lobbying is used: $x^{*}=\tilde{x}$ and $p_{a}^{*}=p_{\emptyset}^{*}=0$.

The statement is rendered more precise in the Appendix. For 'extreme' costs of political pressure - as with a private test - only one lobbying instrument is used. The intuition is the same as for the private test. For intermediate costs, however, the option of a public test drives a wedge between the two parameter spaces that are relevant with a private test.

Two remarks are in order here. First, it is not true that with one type of test there is always a higher level of informational lobbying than with the other one. Consider the middle interval defined by the public test. The threshold for information provision with a private test lies in this interval. This implies that we have first $x_{P U}^{*}>x_{P R}^{*}$ and then the opposite. Second, the fact that in the benchmark informational lobbying starts for lower $\frac{k_{p}}{\Delta}$ with a public test than with a private one seems to dependent on the functional form of $E \Pi_{L}(q) .{ }^{27}$

Therefore, the implication we want to stress here is simply that given an attitude toward risk (that is $\frac{k_{p}}{\Delta}$ ) both tests may create different lobbying behaviors. The conditions of the information game matter not only for informational lobbying but also for political pressure.

$\overline{26}$ Note that for a large shock in the costs of pressure that brings the system from case (i) in Proposition 4.1 to case (ii), pressure is substituted for information. This is the sense in which Bennedsen and Feldmann (2005) predict a substitutive relationship. Our definitions concerning this relationship rely on marginal changes. 27 A micro-foundation generating a function that is for $q \leq \frac{1}{2}$ as in in Figure 2 and for $q \geq \frac{1}{2}$ first convex and then concave could in principle lead to information provision with a private test but not with a public one. 
Propositions 4.1 and 4.2 imply that, in the same vain as in Corollary 3.1, the public test is in the benchmark model always at least weakly preferred.

\subsection{A Politician with Bargaining Power}

Suppose that when the pressure game is reached the lobby cannot just exert political pressure at the exact amount of the reservation value of the politician. Rather the politician can solicit a campaign contribution and doing so has some monopoly power. ${ }^{28}$ Assume that the precise amount is determined by negotiations between the lobby and the legislator. We use the generalized Nash bargaining solution, where $\alpha$ represents the lobby's bargaining power:

$$
\max _{p}\left(V_{B}-k_{p} p^{2}\right)^{\alpha}\left(k_{p} p^{2}-k_{p} \tilde{p}\left(q_{x}, R\right)^{2}\right)^{(1-\alpha)} \Rightarrow p^{*}=\sqrt{(1-\alpha) \frac{V_{B}}{k_{p}}+\alpha \tilde{p}\left(q_{x}, R\right)^{2}} .
$$

The contribution is the higher, the larger the value of policy $B$ for the lobby and the higher the reservation value $\tilde{p}\left(q_{x}, R\right)$ of the politician. It decreases in its costs $k_{p}$. The bargaining power of the politician diminishes the payoffs $E \Pi_{L}\left(q_{x}, R, p^{*}\right)=\alpha\left[V_{B}-k_{p} \tilde{p}\left(q_{x}, R\right)^{2}\right]$ of the lobby proportionally.

In order to show that the incentives for informational lobbying are increased, assume that the cost of pressure are so low that in the benchmark there is no informational lobbying. For simplicity suppose also the use of a public test. ${ }^{29}$ The next proposition is straightforward and stated without proof.

Proposition 4.3 Let $\frac{k_{p}}{\Delta}<\frac{1}{R^{2}}$, assume that the lobby uses a public test and

28 "If one party becomes extortionate ..., it is possible to elect another party which will provide the governmental services [policy $B$ ] at a price more closely proportioned to costs of the party. If entry into politics is effectively controlled, we should expect one-party dominance to lead that party to solicit requests for protective legislation but to extract a higher price for the legislation" Stigler (1971), p. 13.

29 The higher the costs, the less important is bargaining and the more the results resemble those of the benchmark. For a given $\frac{k_{p}}{\Delta}$ the public test is preferred if $\alpha$ is low enough. The assumption that after successful informational lobbying no bargaining takes place is stronger than needed and made for simplicity of the exposition. One could assume that the lobby's bargaining power depends on the test result and, thus, (negatively) on the posterior belief $q_{x}: 0 \leq \alpha(1) \leq \alpha\left(q_{0}\right) \leq \alpha(0) \leq 1$. As long as $\alpha$ is not constant, the effects presented here are present. From the expression for $x^{*}$ (derived next) we can see that a small difference in bargaining powers might generate already qualitatively very different results, provided the costs of pressure are low. If $\alpha$ is constant, a sufficient increase in the costs of political pressure makes the provision of information advantageous (as in the previous subsection). 
suppose that $k_{i}$ is high enough so that $x^{*}<1$. The optimal level of informational lobbying is given by

$$
x^{*}=\max \left\{0, \frac{1}{2 k_{i}}\left[(1-\alpha)\left(1-q_{0}\right) V_{B}+\alpha k_{p} R^{2}\left(\left(2 q_{0}-1\right)^{2}-q_{0}\right)\right]\right\} .
$$

This is positive if $\alpha$ is low or $V_{B}$ is high. In this case political pressure and informational lobbying are employed together and complementary.

It is insightful to gain some intuition for this result. Giving bargaining power to the politician changes the relative profitability of both lobbying instruments and makes information provision advantageous. ${ }^{30}$ The next example shows that despite a complementary relationship reducing information provision, considerable informational lobbying might take place, provided $\alpha$ is low.

Example 4.1 Let $q_{0}=\frac{3}{4}, \alpha=\frac{1}{5}, V_{B}=\Delta=1$ and $k_{i}=\frac{1}{10}$. Over the parameter space $\frac{k_{p}}{\Delta} \in\left[0, \frac{1}{R^{2}}\right], x^{*}$ decreases linearly from $x^{*}=1$ to $x^{*}=\frac{1}{2}$.

Suppose that $x^{*}=0$ for low $\frac{k_{p}}{\Delta}$. Does an increase in the cost of pressure result in information provision? The answer is no and can be illustrated by analyzing how the marginal returns from informational lobbying change with the cost of pressure: $\frac{\partial^{2} E \Pi_{L}(x)}{\partial x \partial k_{p}}=\alpha R^{2}\left(\left(2 q_{0}-1\right)^{2}-q_{0}\right)<0$. Raising the costs of pressure has two opposite effects on the profitability of informational lobbying.

First, there is a relative price effect $R P E=\alpha R^{2}\left(2 q_{0}-1\right)^{2}$. The more often the test fails, the more often a subgame is reached in which - although the optimal pressure level decreases - the payoffs are negatively affected. The more information provided, the less often the test fails. Therefore, the $R P E$ is always positive and works in favor of informational lobbying.

Second, there is a deterrence effect $D E T=-\alpha R^{2} q_{0}$. The more often the test is successful, the more often the negative strategic effect applies, it becomes more difficult to reach the lobby's aim and the lobby wants to correct the outcome of informational lobbying. This provides incentives to provide less information in the first place and so the $D E T$ is always negative. ${ }^{31}$ For low costs of pressure the DET overwhelms the RPE and thus the overall effect is always negative. Therefore, when there is no informational lobbying the deterrence effect impedes this instrument to become profitable. ${ }^{32}$

$\overline{30}$ The function $E \Pi_{L}(q)$ in Figure 2 is pushed downwards. When it lies below the chord connecting $\left(0, E \Pi_{L}(0)\right)$ and $\left(1, E \Pi_{L}(1)\right)$ information is provided although $E \Pi_{L}(q)$ remains concave for high $q$.

31 Note that $\frac{\partial\left(-E \Pi\left(q_{0}, k_{p}, p^{*}\right)\right)}{\partial k_{p}}=R P E$ and $\frac{\partial\left(q_{0} E \Pi\left(1, k_{p}, p^{*}\right)\right)}{\partial k_{p}}=D E T$.

32 If these costs increase further than the interval considered here, it is no longer feasible to exert pressure after revealing the state $a$. At this point a switch occurs, 
It turns out that when there is informational lobbying, that is, $x^{*}>0$, the effect of a change in the costs of pressure on $x^{*}$ depends on the same effects. However, now they induce a complementary relationship between both lobbying instruments, since $\frac{\partial x^{*}}{\partial k_{p}}=\frac{1}{2 k_{i}} \frac{\partial^{2} E \Pi_{L}(x)}{\partial x \partial k_{p}}$. Thus, both when $x^{*}=0$ and $x^{*}>0$ the pressure activity has a deterrence effect on information provision.

We show now that with a private test the same forces are at play.

Example 4.2 Suppose the use of a private test and the parameter values from Example 4.1. The first order condition (derived from equation (1)) characterizes a global maximizer and is given by $(1-\alpha)-\alpha \beta\left(4 q(x)^{2}-1\right)=\frac{4}{5} x$, where $\beta$ parameterizes the whole interval $\frac{k_{p}}{\Delta} \in\left[0, \frac{1}{R^{2}}\right]$ and is defined by $k_{p}=\frac{\beta}{R^{2}}$. As with a public test, we have $x^{*}=1$ for $\beta=0$. However, for $\beta=0.99$ and $\beta=1$ we have $x^{*}=0.5142$ and $x^{*}=0.5107$, respectively. The payoffs are $E \Pi_{L}^{P R}\left(x^{*}=0.5142\right)=0.187$ and $E \Pi_{L}^{P R}\left(x^{*}=0.5107\right)=0.186$. Exclusive pressure obtains $E \Pi_{L}^{P}\left(p^{*}\right)=0.1505$ and $E \Pi_{L}^{P}\left(p^{*}\right)=0.15$. Using only informational lobbying gives $E \Pi_{L}^{I}\left(x^{*}=1\right)=0.156$ independent of $\beta$. In Example 4.1 $E \Pi_{L}^{P U}\left(x^{*}=0.5\right)=0.175$ for $\beta=1$,

Together with Example 4.1, Example 4.2 has several implications:

- With both tests informational lobbying and political pressure might be combined for very low costs of the latter.

- With both tests the instruments might be complementary.

- The optimal political pressure and information level might be different depending on the test.

- The lobby might prefer the private test and provide information voluntarily. Although lowering $\alpha$ further reverses this preference, this shows that Corollary 3.1 captures a general tendency but is not a general result.

\subsection{Uncertainty over the Type of Politician}

Suppose that when the pressure game is reached the lobby cannot just exert political pressure at the exact amount of the reservation value $\tilde{p}\left(q_{x}, R\right)$ of the politician, because he does not know what this value is exactly. Suppose the group is incompletely informed about the information the politician has. While the politician knows the exact value of $q_{0}$, the lobby only knows the distribution of $q_{0}$. To allow the derivation of a closed form solution, assume that $q_{0}$ is uniformly distributed on the line segment $\left[\frac{1}{2}, 1\right]$. This captures realistically that the interest group is not sure how convinced the politician is

implying that the marginal benefit of informational lobbying increases. When this relationship has continued long enough, a positive investment in information is optimal and both lobbying instruments are substitutes. 
that $A$ is the correct decision. ${ }^{33}$

We analyze now the optimal level of political pressure given the result of informational lobbying. Suppose a public test has been used and state $a$ has been revealed. Analogously to the benchmark, $p_{a}^{*} \in\{0, R\}$ because it is clear that the politician has the highest possible posterior.

When the public test fails, the lobby's problem is more involved. Solving equation (3) for $q_{0}$ yields that there exists a critical value $\tilde{q}(p, R) \equiv \frac{(p+R)}{2 R}=\frac{p}{2 R}+\frac{1}{2}$ such that the politician chooses policy $B$ if and only if $q_{0} \leq \tilde{q}(p, R)$. Any given level of pressure $p$ convinces the politician to choose alternative $B$ for any level of $q_{0}$ smaller than the threshold level $\tilde{q}(p, R)$; i.e. only if the politician is relatively unsure that the correct choice is $A$. If $p=0$, then $\tilde{q}(p, R)=\frac{1}{2}$. The problem of the interest group is

$$
\begin{aligned}
\max _{p} E \Pi_{L}(p) & \Leftrightarrow \max _{p} \int_{\frac{1}{2}}^{\tilde{q}(p, R)} V_{B} d F\left(q_{0}\right)+\int_{\tilde{q}(p, R)}^{1} V_{A} d F\left(q_{0}\right)-k_{p} p^{2} \\
& \Leftrightarrow \max _{p} V_{A}+\Delta \frac{p}{R}-k_{p} p^{2} .
\end{aligned}
$$

It is straightforward to solve this problem. For any $R$, we have that $p_{\emptyset}^{*}=R$ if $\frac{k_{p}}{\Delta} \leq \frac{1}{2 R^{2}}$ and $\frac{1}{2 R} \frac{\Delta}{k_{p}}$ otherwise. In the former case $E \Pi_{L}\left(R, p_{\emptyset}^{*}\right)=V_{B}-k_{p} R^{2}$ and $E \Pi_{L}\left(R, p_{\emptyset}^{*}\right)=V_{A}+\Delta \frac{1}{4 R^{2}} \frac{\Delta}{k_{p}}$ in the latter.

The next Lemma indicates the choice of $p^{*}$ depending on the result of the public test. We also use Lemma 4.1 to define three regions of the parameter space that we will refer to in the remainder of the subsection.

Lemma 4.1 Consider a public test.

(i) Region 1: For $\frac{k_{p}}{\Delta} \leq \frac{1}{2 R^{2}}$, we have that $p_{a}^{*}=p_{\emptyset}^{*}=R$.

33 This informational asymmetry could be generated by a signal about the likelihood of the two states of the world that only the politician receives. The lobby, therefore, stays with his uninformative prior. Alternatively, we could assume that the lobby is uncertain about the stakes $R$ of the politician. Wright (1996, p. 82) argues that legislators are motivated (in part) by the basic goals of reelection and successful policy: "The attainment of these goals is complicated by the fact that legislators cannot be certain about how voters will react to their policy decisions, [and] how policies will actually work once implemented ...". While we interpret uncertainty over $R$ as related to voter reactions, we belief that uncertainty over $q_{0}$ captures uncertain adequacy of policies. If legislators face this uncertainty, then it is realistic to assume that this is even more true for a third party that has not made any investment in reducing this uncertainty. Assuming uncertainty on $R$ does not change the results. Detailed calculations are available upon request (and for the convenience of the referees included in Appendix B.2 not intended for publication). 
(ii) Region 2: For $\frac{1}{2 R^{2}}<\frac{k_{p}}{\Delta}<\frac{1}{R^{2}}$, we have that $0<p_{\emptyset}^{*}=\frac{1}{2 R} \frac{\Delta}{k_{p}}<p_{a}^{*}=R$.

(iii) Region 3: For $\frac{1}{R^{2}} \leq \frac{k_{p}}{\Delta}$, we have that $0=p_{a}^{*}<p_{\emptyset}^{*}=\frac{1}{2 R} \frac{\Delta}{k_{p}}<R$.

Consider now a private test. The negative strategic effect adjusts $\tilde{q}(p, R)$ to

$$
\tilde{q}(p, R, x) \equiv \frac{(p+R)(1-x)}{2 R-x(p+R)}
$$

Since $\frac{\partial \tilde{q}(p, R, x)}{\partial x} \leq 0$, the higher the quality of the test, the lower the threshold value $\tilde{q}(p, R, x)$. For a given level of pressure politicians with a relatively high prior probability $q_{0}$ are no longer induced to choose as the lobby wishes although for $x=0$ the pressure level was sufficient.

The effect of the uncertainty is that exerting pressure becomes less reliable and, hence, less profitable as in the benchmark. Under uncertainty there may be some types of politicians who resist pressure. We show now that this induces risk proclivity and analogous results to Corollary 3.1 (i) are always true. ${ }^{34}$

The optimal test choice of the lobby is formalized in the following Proposition.

Proposition 4.4 The lobby always weakly prefers the public test. For regions 1 and 2 , that is, $\frac{k_{p}}{\Delta}>\frac{1}{2 R^{2}}$, this preference is strict.

The next result characterizes the optimal lobbying behavior. ${ }^{35}$

Proposition 4.5 With a public test the lobby combines always informational lobbying with political pressure. Political pressure and informational lobbying are complements almost everywhere in region 2 , that is, for $\frac{k_{p}}{\Delta} \in\left[\frac{1}{\sqrt{3}} \frac{1}{R^{2}}, \frac{1}{R^{2}}\right]$ and substitutes everywhere else.

Contrary to the benchmark, uncertainty over the politician's type creates strong incentives for informational lobbying. Optimal lobbying behavior always uses both instruments. This conclusion does not depend on the availability of the public test. In the proof of Proposition 4.4 we show that in region $1, p_{M}^{*}=R$ for both tests. Hence, the objective functions for informational lobbying and the optimal amount of information provided coincide.

Corollary 4.1 In region 1, that is, $\frac{k_{p}}{\Delta}<\frac{1}{2 R^{2}}$, the optimal lobbying behavior

$\overline{34}$ The function $E \Pi_{L}(q)$ in Figure 2 becomes piece-wise linear and lies below the chord connecting $\left(0, E \Pi_{L}(0)\right)$ and $\left(1, E \Pi_{L}(1)\right)$.

35 To simplify the exposition of the statement we abstract from $\frac{k_{p}}{\Delta}=\frac{1}{R^{2}}$, where the complementarity drives the information provided to zero before it increases again with the substitutive relationship. For the amount of information to respond to changes in $\frac{k_{p}}{\Delta}$ we also implicitly assume that $k_{i}$ is high enough so that $x^{*}<1$. 
does not depend on the test available.

The relationship between both lobbying instruments is again determined by the interplay of the deterrence and the relative price effect. In region 1, for low pressure cost, the deterrence effect is lower than the relative price effect resulting in a substitutive relationship. Since the correction of the negative strategic effect of informational lobbying by applying pressure becomes more expensive as the costs of pressure increase, the deterrence effect overwhelms the relative price effect in region 2. Hence, for intermediate costs the relationship is complementary. In region 3 pressure costs are so high that the correction activity is unprofitable and the deterrence effect is zero. The instruments are again substitutes.

\section{Concluding Remarks}

We have presented a model in which an interest group can strategically provide verifiable policy-relevant information and exert political pressure. Our analysis contributes toward an integration of two largely separated literatures analyzing each lobbying instrument in isolation. Our key findings which are summarized in the Introduction have important policy implications.

For instance, concerning the motivating FDA regulation example, we can say that, since pharmaceutical companies must be required to provide information, we should expect them to have an incentive not to register their clinical trials and to report results selectively. Our analysis lends therefore support for the efforts of the International Committee of Medical Journal Editors (ICMJE) and the World Health Organization (WHO) as well as the proposed Fair Access to Clinical Trials (FACT) Act in the U.S. which aim at promoting registration of all clinical trials. The industry position that endorses voluntarily disclose of information about clinical drug trials but does not include a legal requirement for disclosure does not seem to be sufficient. ${ }^{36}$ Further policy implications of our analysis concerning campaign finance regulation are explored in Dahm and Porteiro (2005). In this concluding section we discuss now some of our simplifying assumptions and future research.

Supposing verifiable reports has helped us to make a clear connection between informational lobbying and lotteries over uncertain outcomes. Alternatively, informational lobbying has been modelled without this assumption (see e.g. Austen-Smith and Wright (1992)). Still, in such a setting the result of informational lobbying is uncertain and depends, for instance, on the legislators checking strategy.

$\overline{36}$ See EFPIA (2005). 
The assumption of the availability of a commitment device not to hold back information allowed us to identify a 'rationale for credibility' that does not rely on reputation effects in a repeated game framework. The concern of lobbies to be credible - stressed in the descriptive literature on lobbying - is rationalized entirely by the lobby's aim to limit the negative strategic effect of informational lobbying on the continuation game. ${ }^{37}$ Although both tests postulated are extreme benchmark cases, they capture realistically that a lobby has some freedom to choose its degrees of credibility when transmitting information. Suppose there is a continuum of experts characterized by a probability $z \in[\underline{z}, \bar{z}] \subseteq[0,1]$ determining whether the lobby will be able to hold back information. We can think of $z$ as a linear combination between a public and a private test. Our analysis implies that the lobby always prefers to be as credible as possible $(\underline{z})$ or to maximize the scope for manipulation $(\bar{z})$ depending on its attitude toward risk. ${ }^{38}$

Another important assumption is that there is only one lobby. Although there are many political decisions in which the advocates of one side of an issue are not organized and can therefore not coordinate on an effective lobbying strategy, situations in which competitive lobbying takes place are clearly relevant. ${ }^{39}$ However, the results in Section 3 do not depend on a precise formulation of the pressure game and there could be competitive political pressures.

With multiple information providers other strategic effects may come into play. ${ }^{40}$ Is it possible that one lobby 'specializes' in information provision, while the other 'specializes' in exerting political pressure? Our analysis invites the conjecture that such a situation could be generated by different stakes. For one lobby stakes are high, pressure is profitable, risk aversion is induced

\footnotetext{
${ }^{37}$ Note also that the negative strategic effect arises because the politician is assumed to observe the lobby's investment in information. This assumption is also made in models without verifiability (see e.g. Austen-Smith and Wright (1992)). In a model with verifiable information, Bennedsen and Feldmann (2005) show that if the politician is rational and forms optimal expectations about the incentives of the lobby to acquire information, she will, in equilibrium, update her beliefs after a lobby's failed report, even if the lobby's activity is unobservable.

38 Note that, although we identify a strong incentive to provide information credibly, Examples 3.2 and 4.2 show that our model can also yield the prediction that less credible information might be provided voluntarily.

39 But note that e.g. Schlozman and Tierney (1986, p. 213) report a number of works finding that in a majority of cases and studies only lobbies on one side of an issue were active. Also, for the interpretation of issue ad spending as political pressure, The Annenberg Public Policy Center (2005) reports that this spending is usually very uneven so that one side of an issue dominates the public policy debate. 40 Bennedsen and Feldmann (2005) have shown that competition among information providers has the interesting effect to reduce the incentives for information provision when political pressure is available.
} 
and no informational is provided. For the other group stakes are low, pressure is not feasible and risk proclivity results in informational lobbying.

A more careful analysis could build upon an analogy to Bulow et al (1985). From their analysis concerning oligopoly markets one conjects that the result of competitive lobbying depends on (1) joint economies or diseconomies among the lobbying instruments of one lobby and on (2) whether lobbies' regard their, say informational activity, as a strategic substitute or complement to the informational activity of other lobbies. Since joint economies (diseconomies) have a close relationship to complementary (substitutive) lobbying instruments, our paper suggests that there may be both joint economies or diseconomies. ${ }^{41}$ But this falls short from determining the overall effect. Further research on the strategic interaction of lobbying instruments and the effect of regulation should be fruitful.

Examples 3.1 and 3.2 suggest that the basic forces we have identified are also active in other situations of information transmission where political pressure is not available. Although, these situations require to be modelled carefully, our analysis suggests that these situations can be understood in a similar vain: the institutions of information transmission as lotteries and the continuation game as determining the attitude toward risk.

\section{References}

[1] Aghion, Philippe and Jean Tirole (1997), "Formal and Real Authority in Organizations," Journal of Political Economy 105, 1-29.

[2] Annenberg Public Policy Center (2005), "Legislative Issue Advertising in the 108th Congress," University of Pennsylvania, available at http://www.annenbergpublicpolicycenter.org/issueads05/ Source\%20Files/APPC_IssueAds108thMM . pdf.

[3] Austen-Smith, David (1995), "Campaign Contributions and Access," American Political Science Review 89, 566-81.

[4] Austen-Smith, David (1997), "Interest Groups: Money, Information, and Influence," in Perspectives on Public Choice. A Handbook, D. C. Mueller ed. (Cambridge, England: Cambridge University Press), 296-320.

[5] Austen-Smith, David (1998), "Allocating Access for Information and Con-

\footnotetext{
$\overline{41}$ A basic intuition of the concept of joint economies is that an improvement in the 'conditions of one market', that is, a decrease in the cost of pressure, goes hand in hand with an improvement of the conditions in the other market. This should lead to an increase in the optimal investment in information. On the other hand, by a similar reasoning, an increase in the cost of pressure leads to a reduction in the level of information provided. Both lobbying instruments are then complements.
} 
tributions," The Journal of Law, Economics and Organization 14 (2), 277303.

[6] Austen-Smith, David and John R. Wright (1992), "Competitive Lobbying for a Legislator's Vote," Social Choice and Welfare 9, 229-257.

[7] Baye, Michael R.; Kovenock, Dan and Casper G. de Vries (1993), "Rigging the Lobbying Process: An Application of the All-Pay Auction," The American Economic Review 83 (1), 289-294.

[8] Bennedsen, Morten and Sven Feldmann (2005), "Informational Lobbying and Political Contributions," Journal of Public Economics, forthcoming.

[9] Bennedsen, Morten and Sven Feldmann (2002), "Lobbying Legislatures," Journal of Political Economy 110 (4), 919-946.

[10] Berry, Jeffrey M. (1997), "The Interest Group Society," 3rd ed. New York: Longman.

[11] Bulow, Jeremy I.; John D. Geanakolos and Paul D. Klemperer (1985), "Multimarket Oligopoly: Strategic Substitutes and Complements," Journal of Political Economy 93 (3), 488-511.

[12] Cannon, Christopher P. et al (2004), "Intensive versus Moderate Lipid Lowering with Statins after Acute Coronary Syndromes," New England Journal of Medicine 350 (15), 1495-1504.

[13] Carpenter (2004), "The Political Economy Of FDA Drug Review: Processing, Politics, And Lessons For Policy," Health Affairs 23 (1), 52-63.

[14] Che, Yeon-Koo and Ian L. Gale (1998), "Caps on Political Lobbying," The American Economic Review 88 (3), 643-651.

[15] Crawford, Vince and Joel Sobel (1982), "Strategic Information Transmission," Econometrica 50, 105-133.

[16] Dahm, Matthias and Nicolás Porteiro (2003), "The Political Economy of Interest Groups: Pressure and Information," CORE Discussion Paper 2003/57, Catholic University of Louvain.

[17] Dahm, Matthias and Porteiro Nicolás (2005), "Side-Effects of Campaign Finance Reform," unpublished manuscript.

[18] EFPIA (2005), "Joint Position on the Disclosure of Clinical Trial Information via Clinical Trial Registries and Databases," January, available at www.efpia.org/4_pos/sci_regu/Clinicaltrials2005.pdf

[19] Grossmann, Gene M. and Elhanan Helpman (2001), "Special Interest Politics," Cambridge MA and London UK: The MIT Press.

[20] ICMJE (2004), "Clinical Trial Registration: A Statement from the International Committee of Medical Journal Editors," New England Journal of Medicine 351 (12), available at www.icmje.org/clin_trial.pdf

[21] Laffont, Jean-Jacques (1999), "Political Economy, Information and Incentives," Presidential Address, European Economic Review 43, 649-669.

[22] Laffont, Jean-Jacques and Jean Tirole (1993), "A Theory of Incentives in Procurement and Regulation," Cambridge, Mass.: The MIT Press.

[23] Lohmann, Susanne (1995a), "Information, Access, and Contributions: A Signaling Model of Lobbying," Public Choice 85 (3-4), 267-84.

[24] Lohmann, Susanne (1995b), "A Signaling Model of Competitive Political 
Pressures," Economics and Politics 5, 181-206.

[25] Matějka, Michal; Onderstal, Sander and Anja de Waegenaere (2002), "The Effectiveness of Caps on Political Lobbying," CentER Discussion Paper No. 2002-44, Tilburg University.

[26] Meadows, Michelle (2002), "The FDA's Drug Review Process: Ensuring Drugs are Safe and Effective," FDA Consumer magazine, JulyAugust, available at http://www.fda.gov/fdac/features/2002/402_ drug.html.

[27] Milgrom, Paul (1981), "Good News and Bad News: Representation Theorems and Applications," Bell Journal of Economics 12, 380-391.

[28] Shin, Hyun Song (2003), "Disclosures and Asset Returns," Econometrica 71 (1), 105-133.

[29] Schlozman, Kay Lehman and John T. Tierney (1986), "Organized Interests and American Democracy," New York: Harper and Row.

[30] Sloof, Randolph and Frans van Winden (2000), "Show them your teeth first! A game-theoretic analysis of lobbying and pressure," Public Choice 104, 81-120.

[31] Snyder, James M. Jr. (1991), "On Buying Legislatures," Economics and Politics 2 (3), 93-109.

[32] Stigler, George J. (1971), "The Theory of Economic Regulation," Bell Journal of Economics 2 (1), 3-21.

[33] Wright, John R. (1990), "Contributions, Lobbying, and Committee Voting in the U.S. House of Representatives," The American Political Science Review 84 (2), 417-438.

[34] Wright, John R. (1996), "Interest Groups and Congress: Lobbying, Contributions, and Influence," Boston: Allyn \& Bacon.

[35] Yu, Zhihao (2005), "Environmental Protection: A Theory of Direct and Indirect Competition for Influence," Review of Economic Studies 72, 269286.

\section{A Appendix: Proofs}

\section{A.1 Proof of Proposition 3.1}

From equations (1) and (2), $\forall x \in(0,1) E \Pi_{L}^{P U}(x) \leq E \Pi_{L}^{P R}(x)$ if and only if $x q_{0} E \Pi_{L}\left(q_{x}=1\right)+(1-x) E \Pi_{L}\left(q_{x}=q_{0}\right) \leq\left(1-x\left(1-q_{0}\right)\right) E \Pi_{L}\left(q_{x}=q(x)\right)$.

Define the LHS as $E \Pi_{L}^{P U}(x \mid t \neq b)$ and the RHS as $E \Pi_{L}^{P R}(x \mid t \neq b)$. Consider first the following Lemma. 
Lemma A.1 The function $E \Pi_{L}^{P R}(x \mid t \neq b)$ is such that:

$$
\frac{\partial^{2} E \Pi_{L}^{P R}(x \mid t \neq b)}{\partial x \partial x}=\left(1-q_{0}\right) q(x) \frac{\partial q(x)}{\partial x} \frac{\partial^{2} E \Pi_{L}\left(q_{x}=q(x)\right)}{\partial q \partial q} .
$$

Proof of Lemma A.1: Follows from straightforward computation of the first two derivatives of $E \Pi_{L}^{P R}(x \mid t \neq b)$.

This lemma establishes a one to one correspondence between the curvature of $E \Pi_{L}^{P R}(x \mid t \neq b)$ with respect to $x$ and that of $E \Pi_{L}$ with respect to $q$. Since $\left(1-q_{0}\right) q(x) \frac{\partial q(x)}{\partial x}>0$, if follows that the function $E \Pi_{L}^{P R}(x \mid t \neq b)$ is convex (concave/ linear) in $x$, if and only if $E \Pi_{L}$ is convex (concave/ linear) in $q$. Given that $E \Pi_{L}^{P U}(x \mid t \neq b)$ is a linear function in $x$ and $E \Pi_{L}^{P U}(x \mid t \neq b)=$ $E \Pi_{L}^{P U}(x \mid t \neq b)$ for $x \in\{0,1\}$, parts (i), (ii) and (iii) follow.

Q.E.D.

\section{A.2 Proof of Proposition 3.2}

Suppose a public test. From equation (2) we obtain the first order condition

$\frac{\partial E \Pi_{L}^{P U}(x)}{\partial x}=\left(1-q_{0}\right) E \Pi_{L}\left(q_{x}=0\right)+q_{0} E \Pi_{L}\left(q_{x}=1\right)-E \Pi_{L}\left(q_{x}=q_{0}\right)-C^{\prime}(x) \equiv 0$.

Given $C^{\prime \prime}(x)>0$, the second order condition for a maximizer is fulfilled. The amount of information bought $x^{*}$ is strictly positive if and only if

$$
\left(1-q_{0}\right) E \Pi_{L}(q=0)+q_{0} E \Pi_{L}(q=1)>E \Pi_{L}\left(q=q_{0}\right) .
$$

Since $q_{0}=\left(1-q_{0}\right) 0+q_{0} 1$, this requirement is fulfilled if the function $E \Pi_{L}(q)$ is strictly convex in $q$. If $E \Pi_{L}(q)$ is concave in $q$, then $x^{*}=0$.

Suppose a private test. Computing the first derivative of equation (1) yields

$$
\left(1-q_{0}\right)\left(E \Pi_{L}\left(q_{x}=0\right)+\frac{\partial E \Pi_{L}\left(q_{x}=q(x)\right)}{\partial q} q(x)-E \Pi_{L}\left(q_{x}=q(x)\right)\right)-C^{\prime}(x)
$$

Assume $E \Pi_{L}(q)$ is strictly convex in $q$ and that $x^{*}=0$. Optimality requires that at $x^{*}=0$ the previous derivative is non-positive, or equivalently

$$
E \Pi_{L}\left(q_{x}=0\right) \leq E \Pi_{L}\left(q_{x}=q_{0}\right)-\frac{\partial E \Pi_{L}\left(q_{x}=q_{0}\right)}{\partial q} q_{0}
$$


This contradicts the convexity of $E \Pi_{L}(q)$ in $q \cdot{ }^{42}$ Assume now that $E \Pi_{L}(q)$ is concave in $q$. Since the second order condition is given by the expression in Lemma A.1 minus $C^{\prime \prime}(x)$, it is strictly concave and the first order condition determines a global maximizer. A necessary condition for $x^{*}>0$ is that, there exists an $x$ such that

$$
E \Pi_{L}\left(q_{x}=0\right)-E \Pi_{L}\left(q_{x}=q(x)\right)+\frac{\partial E \Pi_{L}\left(q_{x}=q(x)\right)}{\partial q} q(x)>0 .
$$

Since $E \Pi_{L}(q)$ is concave for all $q$, such $x$ does not exist.

Q.E.D.

\section{A.3 Proof of Proposition 4.1}

To render the statement more precise, the threshold postulated in the proposition is $\frac{1}{\tilde{p}\left(q_{0}, R\right)^{2}}\left(1-\frac{\left(1-q_{0}\right)^{2}}{4} \frac{\Delta}{k_{i}}\right)$ if $x^{*}<1$ and $\frac{1}{\tilde{p}\left(q_{0}, R\right)^{2}}\left(q_{0}+\frac{k_{i}}{\Delta}\right)$ otherwise.

We show first that the lobby never uses both instruments. Suppose it does and $\tilde{p}(q(x), R)$ is profitable (or $\left.\frac{k_{p}}{\Delta} \leq \frac{1}{(2 q(x)-1)^{2} R^{2}}\right)$. Denote this activity by $I P$. Using equation (1) and denoting the choice of exclusive pressure without informational lobbying by $P$ yields $\gamma(x)=E \Pi_{L}^{P}-E \Pi_{L}^{I P}(x) \geq 0$

$$
\Leftrightarrow-k_{p}\left(2 q_{0}-1\right)^{2} R^{2}+\left(1-x\left(1-q_{0}\right)\right) k_{p}(2 q(x)-1)^{2} R^{2}+k_{i} x^{2} \geq 0
$$

At $x=0, \gamma(x)=0\left(\right.$ since $\left.E \Pi_{L}^{I P}(x=0)=E \Pi_{L}^{P}\right)$. Moreover,

$$
\frac{\partial \gamma(x)}{\partial x}=\left(1-q_{0}\right) k_{p} R^{2}(2 q(x)-1)(2 q(x)+1)+2 k_{i} x>0, \forall x .
$$

Therefore, for a given level of informational lobbying $x$, the lobby either prefers $P$ to $I P$ or $I P$ is not feasible and the choice must be made between $P$ and informational lobbying $I$ only. Thus, it remains to proof that $I$ is preferred to $P$ if and only if the condition of the Proposition is fulfilled. We have,

$$
\begin{aligned}
& E \Pi_{L}^{P} \geq E \Pi_{L}^{I}(x)=x\left(1-q_{0}\right) V_{B}+\left(1-x\left(1-q_{0}\right)\right) V_{A}-k_{i} x^{2} \\
\Leftrightarrow & \left(1-x\left(1-q_{0}\right)\right) \Delta \geq k_{p} \tilde{p}\left(q_{0}, R\right)^{2}-k_{i} x^{2} \Leftrightarrow 1+\frac{k_{i}}{\Delta} x^{2} \geq \frac{k_{p}}{\Delta} \tilde{p}\left(q_{0}, R\right)^{2}+x\left(1-q_{0}\right) .
\end{aligned}
$$

The unique maximizer for $E \Pi_{L}^{I}(x)$ is $x^{*}=\tilde{x}$ as described. We have then that $E \Pi_{L}^{P} \geq E \Pi_{L}^{I}\left(x^{*}\right)$ is determined by the threshold given above. Q.E.D.

$\overline{42 E \Pi_{L}}(q)$ is strictly convex in $q$, if for every $q^{\prime}, q^{\prime \prime}$ it is true that $E \Pi_{L}\left(q^{\prime}\right)>$ $E \Pi_{L}\left(q^{\prime \prime}\right)+\left(q^{\prime}-q^{\prime \prime}\right) \frac{\partial E \Pi_{L}\left(q^{\prime \prime}\right)}{\partial q}$. Define $q^{\prime}=0$ and $q^{\prime \prime}=q_{0}$. 


\section{A.4 Proof of Proposition 4.2}

To render the statement more precise:

- The two thresholds postulated in the proposition are $\frac{q_{0}}{\tilde{p}\left(q_{0}, R\right)^{2}}$ and $\frac{1}{\tilde{p}\left(q_{0}, R\right)^{2}}$.

- For intermediate costs informational lobbying is given by $x^{*}=\min \left\{\frac{1}{2} \frac{1}{k_{i}}\left[k_{p} \tilde{p}\left(q_{0}, R\right)^{2}-q_{0} \Delta\right], 1\right\}$.

Consider the expected profits of combining pressure and information (again denoted by $I P$ ) and given by equation (2). Note that for $x=0, E \Pi_{L}^{I P}(x)=$ $E \Pi_{L}^{P}$ while for $p=0, E \Pi_{L}^{I P}(x)=E \Pi_{L}^{I}$. The latter happens for $\frac{1}{\left(2 q_{0}-1\right)^{2} R^{2}} \leq \frac{k_{p}}{\Delta}$ (no pressure game is affordable). For this case $x^{*}$ has been determined in Proposition 4.1. For lower costs the derivative of $E \Pi_{L}^{I P}(x)$ w.r.t. $x$ is

$$
q_{0} \max \left\{V_{A}, V_{B}-k_{p} R^{2}\right\}+\left(1-q_{0}\right) V_{B}-\left(V_{B}-k_{p}\left(2 q_{0}-1\right)^{2} R^{2}\right)-2 k_{i} x .
$$

Suppose $\frac{k_{p}}{\Delta} \leq \frac{1}{R^{2}}$ (both pressure games are affordable). The first order condition is negative and from Proposition 4.1 follows that only pressure is exerted.

It remains to consider $\frac{1}{R^{2}}<\frac{k_{p}}{\Delta}<\frac{1}{\left(2 q_{0}-1\right)^{2} R^{2}}$ (only the cheaper pressure game is affordable). The first order condition leads to the unique maximizer

$$
\begin{aligned}
x^{*} & =\frac{1}{2 k_{i}}\left[q_{0} V_{A}+\left(1-q_{0}\right) V_{B}-V_{B}+k_{p}\left(2 q_{0}-1\right)^{2} R^{2}\right] \\
& =\frac{1}{2 k_{i}}\left[-q_{0} \Delta+k_{p}\left(2 q_{0}-1\right)^{2} R^{2}\right] \text { and } x^{*} \geq 0 \Leftrightarrow \frac{k_{p}}{\Delta} \geq \frac{q_{0}}{\left(2 q_{0}-1\right)^{2} R^{2}} .
\end{aligned}
$$

We have $\frac{1}{R^{2}} \leq \frac{q_{0}}{\left(2 q_{0}-1\right)^{2} R^{2}} \leq \frac{1}{\left(2 q_{0}-1\right)^{2} R^{2}}$ and, again, if $x^{*}=0$, then $p^{*}=\tilde{p}\left(q_{0}, R\right)$. It remains to check that $I P$ is preferred to $I$. We obtain $E \Pi_{L}^{I P}(x)-E \Pi_{L}^{I}(x)=$ $(1-x)\left(\Delta-k_{p}\left(2 q_{0}-1\right)^{2} R^{2}\right)>0, \forall x$.

Q.E.D.

\section{A.5 Proof of Proposition 4.4}

Define $\gamma(x)=E \Pi_{L}^{P R}(x)-E \Pi_{L}^{P U}(x)$. Note that if $x=0$, then $\gamma(0)=0$. We analyze the three regions separately.

(i) Region 1: By Lemma $4.1 p_{a}^{*}=p_{\emptyset}^{*}=R$ for a public test. For a private test $p_{\emptyset}^{*}=R$, too. (The first derivative of the analogous maximization program to equation (4) using $\tilde{q}(p, R, x)$ is positive at $p=0$ and $p=R$ and it is either convex for low cost and then concave or concave everywhere). Thus, $\gamma(x)=0$. 
(iii) Region 3: By Lemma $4.1 p_{a}^{*}=0$. Therefore,

$$
\gamma(x)=\left(1-x\left(1-E\left(q_{0}\right)\right)\right) E \Pi_{L}\left(q_{x}=q(x)\right)-E\left(q_{0}\right) x V_{A}-(1-x) E \Pi_{L}\left(R, p_{\emptyset}^{*}\right) .
$$

Note that for $x=1$ the updated probability the politician assigns to state $a$ is equal to one. But in region $3, p_{a}^{*}=0$ and hence, if $x$ is sufficiently large, exerting pressure is not profitable. Formally, there exists $\bar{x}$ such that for all $x \geq$ $\bar{x}, E \Pi_{L}\left(q_{x}=q(x)\right)=V_{A}$. For all $x \geq \bar{x}, \gamma(x)=-(1-x)\left(E \Pi_{L}\left(R, p_{\emptyset}^{*}\right)-V_{A}\right) \leq 0$, with equality for $x=1$ and $\gamma^{\prime}(x)>0$ (using the envelope theorem). For all $x \leq \bar{x}$, (using the envelope theorem again),

$$
\begin{aligned}
\gamma^{\prime}(x)= & -\left(1-E\left(q_{0}\right)\right) E \Pi_{L}\left(q_{x}=q(x)\right)+\left(1-x\left(1-E\left(q_{0}\right)\right)\right) 2 \Delta \frac{\partial \tilde{q}(p, R, x)}{\partial x} \\
& -E\left(q_{0}\right) V_{A}+E \Pi_{L}\left(R, p_{\emptyset}^{*}\right) .
\end{aligned}
$$

At $x=0$, we have that $E \Pi_{L}\left(q_{x}=q(x)\right)=E \Pi_{L}\left(R, p_{\emptyset}^{*}\right)$, therefore:

$$
\begin{aligned}
\gamma^{\prime}(x)_{\mid x=0} & =E\left(q_{0}\right)\left(E \Pi_{L}\left(R, p_{\emptyset}^{*}\right)-V_{A}\right)+2 \Delta \frac{\partial \tilde{q}(p, R, x)}{\partial x}_{\mid x=0} \leq 0 \\
& \Leftrightarrow E\left(q_{0}\right)\left(\frac{\Delta^{2}}{4 R^{2} k_{p}}\right)-2 \Delta \frac{(p+R)(R-p)}{4 R^{2}} \leq 0 \Leftrightarrow R^{2}-p^{2} \geq \frac{3}{8} \frac{\Delta}{k_{p}}
\end{aligned}
$$

Since $p^{*}$ is decreasing in $R$, it suffices to check if this inequality holds for the lowest value of $R$ compatible with being in Region 3 . The boundary of this region is given by the condition $\frac{k_{p}}{\Delta}=\frac{1}{R^{2}}$. Therefore, the lowest value of $R$ is $R=\sqrt{\frac{\Delta}{k_{p}}}$. For this level $p^{*}=\frac{1}{2} \sqrt{\frac{\Delta}{k_{p}}}$. It is straightforward to check that for these values (and, hence, for the whole region 3), $\gamma^{\prime}(x)_{\mid x=0} \leq 0$.

Using the envelope theorem again, we derive

$$
\gamma^{\prime \prime}(x)=-2\left(1-E\left(q_{0}\right)\right) 2 \Delta \frac{\partial \tilde{q}(p, R, x)}{\partial x}+\left(1-x\left(1-E\left(q_{0}\right)\right)\right) 2 \Delta \frac{\partial^{2} \tilde{q}(p, R, x)}{\partial x^{2}}
$$

Straightforward calculations show that $\gamma(x)$ is concave.

(ii) Region 2: It suffices to observe that here $\gamma(x)$ is smaller than in region 3 , since $p_{a}=R$, implying that the term $-E\left(q_{0}\right) x V_{A}$ is substituted with $-E\left(q_{0}\right) x\left[V_{B}-k_{p} R^{2}\right]$ and $V_{B}-k_{p} R^{2} \geq V_{A}$ Q.E.D. 


\section{A.6 Proof of Proposition 4.5}

Maximization of (2) yields the optimal level of information

$x^{*}=\min \left\{\frac{1}{2 k_{i}}\left[E\left(q_{0}\right) \max \left\{V_{A}, V_{B}-k_{p} R^{2}\right\}+\left(1-E\left(q_{0}\right)\right) V_{B}-E \Pi_{L}\left(R, p_{\emptyset}^{*}\right)\right], 1\right\}$.

(i) In region 1 , this simplifies (at an interior optimum) to $x^{*}=\frac{1}{2 k_{i}}(1-$ $\left.E\left(q_{0}\right)\right) k_{p} R^{2}>0$ which is increasing in $k_{p}$.

(ii) In region 2 , by Lemma $4.1 p_{\emptyset}^{*}<R$ and $p_{a}^{*}=R$. Thus, (at an interior optimum) $x^{*}=\frac{1}{2 k_{i}}\left\{-E\left(q_{0}\right) k_{p} R^{2}+\Delta-\Delta\left[\frac{1}{2 R^{2}} \frac{\Delta}{k_{p}}\right]+k_{p} p_{\emptyset}^{* 2}\right\}$, which is positive if and only if, $\frac{\Delta}{k_{p}} \geq E\left(q_{0}\right) R^{2}+p_{\emptyset}^{* 2}$. In this region we have that $\frac{\Delta}{k_{p}} \geq R^{2}$ implying that it suffices to show that $R^{2}\left(1-E\left(q_{0}\right)\right) \geq p_{\emptyset}^{* 2}$ which is true. We have that $\frac{\partial x^{*}}{\partial k_{p}}=\frac{-E\left(q_{0}\right) R^{2}+p_{\emptyset}^{* 2}}{2 k_{i}} \leq 0$ if and only if $\frac{k_{p}}{\Delta} \geq \frac{1}{\sqrt{3}} \frac{1}{R^{2}}$.

(iii) In region $3, x^{*}$ simplifies (at an interior optimum) to $x^{*}=\frac{1}{2 k_{i}}[(1-$ $\left.\left.E\left(q_{0}\right)\right) \Delta-\Delta \frac{1}{4 R^{2}} \frac{\Delta}{k_{p}}\right]>0$ which is increasing in $k_{p}$ and positive. Q.E.D.

\section{B Appendix: Not Intended For Publication}

This Appendix is for the convenience of the referees only.

\section{B.1 Further Details for Example 3.2}

We start with a table showing the equivalence of notation in Bennedsen and Feldmann (2002) - BF02 in what follows - and the main body of the paper:

\begin{tabular}{|l|l|l|l|l|l|l|}
\hline BF02 notation & $q$ & $\underline{r}$ & $\bar{r}$ & $b_{i}$ & $p^{0}$ & $u_{L}$ \\
\hline our notation & $x$ & 0 & 1 & 0 & $1-q_{0}$ & $E \Pi_{L}(q)$ \\
\hline
\end{tabular}

The fact that a legislator maximizes $u_{i}=r_{i} g_{i}-\frac{1}{6} G^{2}$ follows from $n=3$ and substitution in the first equation on p. 924 of BF02. Our requirement that the group searches in exactly one district translates to $s=1$ in BF02. Therefore, the lobby maximizes $u_{L}=G^{*}(q)$ - whatever the cost of informational lobbying. This is given by equation (2) in BF02 which simplifies in our example. Define $B=\frac{1}{1-q_{0}}$. We treat this in what follows as a constant because it corresponds to a district in which no search takes place. There are three cases: 
(1) The lobby searches in the agenda setter's district (with probability $\frac{1}{3}$ ). If the search reveals that the agenda setter's marginal valuation is $r_{a}=0$ he proposes $G^{*}=0$. In all other cases he proposes $G^{*}=\frac{3}{\frac{1}{1-q_{x}}+B}$, with $q_{x} \in\left\{0, q_{0}, q(x)\right\}$ depending on the test type and result.

(2) The lobby does not search in the agenda setter's district (with probability $\frac{2}{3}$ ) and the search reveals high marginal valuation $r_{i}=1$ (with probability $\left.x\left(1-q_{0}\right)\right)$. Here $G^{*}=\frac{3}{1+B}$ (which happens with total frequency $\left.\frac{2 x\left(1-q_{0}\right)}{3}\right)$.

(3) The lobby does not search in the agenda setter's district and the search fails or reveals low marginal valuation $r_{i}=0$ (which happens with total frequency $\left.\frac{2\left(1-x\left(1-q_{0}\right)\right)}{3}\right)$. Independent of the test this district is not included in the policy coalition and $G^{*}=\frac{3}{2 B}$.

We have that

$$
\begin{aligned}
& E \Pi_{L}^{P R}(x)=\frac{1}{3}\left[\left(1-x\left(1-q_{0}\right)\right) \frac{3}{\frac{1}{1-q(x)}+B}+x\left(1-q_{0}\right) \frac{3}{1+B}\right] \\
& \frac{2}{3}\left[\left(1-x\left(1-q_{0}\right)\right) \frac{3}{2 B}+x\left(1-q_{0}\right) \frac{3}{1+B}\right], \\
& \left.E \Pi_{L}^{P U}(x)=\frac{1}{3}\left[x q_{0} * 0+(1-x)\right) \frac{3}{2 B}+x\left(1-q_{0}\right) \frac{3}{1+B}\right] \\
& \frac{2}{3}\left[\left(1-x\left(1-q_{0}\right)\right) \frac{3}{2 B}+x\left(1-q_{0}\right) \frac{3}{1+B}\right] \text { and } \\
& E \Pi_{L}^{P R}(x)>E \Pi_{L}^{P u}(x) \Leftrightarrow \frac{3}{\frac{1}{1-q(x)}+B}>\frac{x q_{0} * 0}{\left(1-x\left(1-q_{0}\right)\right)}+\frac{(1-x)}{\left(1-x\left(1-q_{0}\right)\right)} \frac{3}{2 B} .
\end{aligned}
$$

In other words, if and only if, $E \Pi_{L}^{\prime}(q)=\frac{3}{\frac{1}{1-q}+B}$ is strictly concave, which is true. $\left(\frac{\partial E \Pi_{L}^{\prime}(q)}{\partial q}=\frac{-3}{[1+B(1-q)]^{2}}<0\right.$ and $\frac{\partial^{2} E \Pi_{L}^{\prime}(q)}{\partial q \partial q}=\frac{-6 B}{[1+B(1-q)]^{3}}<0$.)

\section{B.2 For Footnote 33: when the Stakes of the Politician are Uncertain}

With uncertainty over $R$ it can be shown:

(1) The public test is preferred (Proposition B.1).

(2) Informational lobbying is favored compared to the benchmark (in Section 4.1) and often used together with political pressure (Proposition B.2).

(3) The relationship between pressure and information might be complementary (this requires a slight asymmetry in the politician's payoffs and is shown in Dahm and Porteiro (2005)). 
The intuition for (1) and (2) is provided by Corollary 3.1. $E \Pi_{L}(q)$ is concave or convex depending on whether the cost of pressure and the (posterior) belief $q$ are high enough. (3) depends again on the relative size of the deterrence and relative prize effect.

Assume that the politician knows the precise value of $R$, while the lobby only knows that $R$ is uniformly distributed on the line segment $[0,1]$. This captures realistically that the lobby does not know how much the decision matters for the politician. As in Subsection 4.3 the lobby does not know exactly how much pressure is necessary in order to induce his preferred policy $B$.

However, he knows that given any (posterior) belief $q_{x}>0$ a level of pressure $p$ convinces the politician to choose alternative $B$ if $R$ is low enough. More formally, there exists a threshold $\tilde{R}\left(p, q_{x}\right) \equiv \frac{p}{2 q_{x}-1}$ such that the politician chooses policy $B$ if and only if $R \leq \tilde{R}\left(p, q_{x}\right)$. If $p=0$, then $\tilde{R}\left(p, q_{x}\right)=0$ and policy $A$ is almost always be chosen. If $p=2 q_{x}-1$, then $\tilde{R}\left(p, q_{x}\right)=1$ and the politician chooses $B$ whatever $R .{ }^{43}$ The problem of the interest group is

$$
\begin{aligned}
\max _{p} E \Pi_{L}\left(q_{x}, p\right) & \Leftrightarrow \max _{p} \int_{0}^{\tilde{R}\left(p, q_{x}\right)} V_{B} d F(R)+\int_{\tilde{R}\left(p, q_{x}\right)}^{1} V_{A} d F(R)-k_{p} p^{2} \\
& \Leftrightarrow \max _{p} V_{A}+\Delta \frac{p}{2 q_{x}-1}-k_{p} p^{2}
\end{aligned}
$$

Analyzing the first and second order conditions leads to the following lemma.

Lemma B.1 Given any (posterior) belief $q_{x}$, we have that $p^{*}\left(q_{x}\right)=2 q_{x}-1$ if $\frac{k_{p}}{\Delta} \leq \frac{1}{2\left(2 q_{x}-1\right)^{2}}$ and $\frac{1}{2\left(2 q_{x}-1\right)} \frac{\Delta}{k_{p}}$ otherwise. Moreover, $E \Pi_{L}\left(q_{x}, p^{*}\right)=V_{B}-k_{p}\left(2 q_{x}-\right.$ $1)^{2}$ if $\frac{k_{p}}{\Delta} \leq \frac{1}{2\left(2 q_{x}-1\right)^{2}}$ and $V_{A}+\Delta \frac{1}{4\left(2 q_{x}-1\right)^{2}} \frac{\Delta}{k_{p}}$ otherwise.

$E \Pi_{L}\left(q_{x}, p^{*}\right)$ is concave or convex depending on whether the cost of pressure and the (posterior) belief $q_{x}$ are high enough.

Lemma B.2 Consider a public test.

(i) For $\frac{k_{p}}{\Delta} \leq \frac{1}{2}$, we have that $p_{a}^{*}=1, p_{\emptyset}^{*}=2 q_{0}-1$.

(ii) For $\frac{1}{2}<\frac{k_{p}}{\Delta}<\frac{1}{2\left(2 q_{0}-1\right)^{2}}$, we have that $p_{a}^{*}<1, p_{\emptyset}^{*}=2 q_{0}-1$.

(iii) For $\frac{1}{2\left(2 q_{0}-1\right)^{2}} \leq \frac{k_{p}}{\Delta}$, we have that $p_{a}^{*}<1, p_{\emptyset}^{*}<2 q_{0}-1$.

Proposition B.1 The lobby always weakly prefers the public test. For high parameter values of $\frac{k_{p}}{\Delta}$, this preference is strict.

We prove that whenever both instruments are used, a public test is preferred.

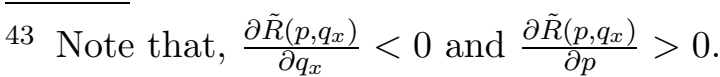


Proof: We study the three intervals, defined in Lemma B.2 separately.

(i) Suppose $\frac{k_{p}}{\Delta} \leq \frac{1}{2}$. We compute the optimal amount of information bought with both tests. Consider a private test. Maximizing equation (1) and using that $E \Pi_{L}\left(q_{0}, x\right)=V_{B}-k_{p}\left(\frac{2 q_{0}-1+x\left(1-q_{0}\right)}{1-x\left(1-q_{0}\right)}\right)^{2}$, the program can be rewritten as $\max _{x} V_{B}-k_{p} \frac{\left(2 q_{0}-1+x\left(1-q_{0}\right)\right)^{2}}{1-x\left(1-q_{0}\right)}-k_{i} x^{2}$. Since this is a strictly decreasing function of $x, x^{*}=0$. Analogously, for a public test, the lobby maximizes equation (2). Computing the first order condition and substituting $E \Pi_{L}\left(q_{x}=1\right)=V_{B}-k_{p}$ and $E \Pi_{L}\left(q_{x}=q_{0}\right)=V_{B}-k_{p}\left(2 q_{0}-1\right)^{2}$, allows to check that $\frac{\partial E \Pi_{L}^{P U}(x)}{\partial x}<0, \forall x$. Therefore, $x^{*}=0$ and the lobby is (trivially) indifferent both tests.

(iii) Suppose $\frac{k_{p}}{\Delta} \geq \frac{1}{2\left(2 q_{0}-1\right)^{2}}$. Define $\gamma(x)=E \Pi_{L}^{P R}(x)-E \Pi_{L}^{P U}(x)$. We have

$$
\begin{array}{r}
\gamma(x)=-(1-x)\left(E \Pi_{L}\left(q_{x}=q_{0}\right)-E \Pi_{L}\left(q_{x}=q(x)\right)\right) \\
+x q_{0}\left(E \Pi_{L}\left(q_{x}=q(x)\right)-E \Pi_{L}\left(q_{x}=1\right)\right) .
\end{array}
$$

Since $E \Pi_{L}\left(q_{x}=q(x)\right)=V_{A}+\frac{\Delta^{2}}{4 k_{p}}\left(\frac{2 q_{0}-1+x\left(1-q_{0}\right)}{1-x\left(1-q_{0}\right)}\right)^{2}$,

$$
\begin{aligned}
\gamma(x)= & -(1-x) E \Pi_{L}\left(q_{x}=q_{0}\right)-x q_{0} E \Pi_{L}\left(q_{x}=1\right)+\left(1-x\left(1-q_{0}\right)\right) V_{A} \\
& +\frac{\Delta^{2}}{4 k_{p}} \frac{\left(2 q_{0}-1+x\left(1-q_{0}\right)\right)^{2}}{1-x\left(1-q_{0}\right)} \text { and } \\
\gamma^{\prime}(x)= & E \Pi_{L}\left(q_{x}=q_{0}\right)-q_{0} E \Pi_{L}\left(q_{x}=1\right)-\left(1-q_{0}\right) V_{A}+ \\
& +\frac{\Delta^{2}\left(1-q_{0}\right)}{4 k_{p}}\left(\frac{2\left(2 q_{0}-1+x\left(1-q_{0}\right)\right)}{1-x\left(1-q_{0}\right)}+\frac{\left(2 q_{0}-1+x\left(1-q_{0}\right)\right)^{2}}{\left(1-x\left(1-q_{0}\right)\right)^{2}}\right) .
\end{aligned}
$$

Because $\gamma^{\prime \prime}(x)>0, \gamma(x)$ is a convex function. Moreover, $\gamma(0)=\gamma(1)=0$ ensures that $\gamma(x) \leq 0$, for every value of $x$. The public test is preferred.

(ii) Assume $\frac{k_{p}}{\Delta} \in\left(\frac{1}{2}, \frac{1}{2\left(2 q_{0}-1\right)^{2}}\right)$. First, for a private test, there exists a threshold $\bar{x}$, such that if $x>\bar{x}$, then the optimal pressure level when the test does not reveal $t=b$ is interior. For these values of $x$ the reasoning of part (iii) applies. If $x \leq \bar{x}$ the problem is as in part (i) and, therefore, $x=0$. For a public test, the lobby maximizes the same function as in part (i) but now in the first order condition $E \Pi_{L}\left(q_{x}=1\right)=V_{A}+\frac{\Delta^{2}}{4 k_{p}}$ must be used. We obtain $x>0 \Leftrightarrow$ $k_{p}\left(2 q_{0}-1\right)^{2}-q_{0}\left(\Delta-\frac{\Delta^{2}}{4 k p}\right)>0$. Rearranging terms, we have that $x>0$ if $\frac{k_{p}}{\Delta}$ is larger than the positive root of $4\left(\frac{k_{p}}{\Delta}\right)^{2}-4 \frac{q_{0}}{\left(2 q_{0}-1\right)^{2}}\left(\frac{k_{p}}{\Delta}\right)+\frac{q_{0}}{\left(2 q_{0}-1\right)^{2}}=0$. This threshold is given by $\frac{k_{p}}{\Delta}=\frac{1}{2\left(2 q_{0}-1\right)^{2}}\left(q_{0}+\sqrt{q_{0}\left(1-q_{0}\right)\left(4 q_{0}-1\right)}\right)$, which is always higher than $\frac{k_{p}}{\Delta}=\frac{1}{2\left(2 q_{0}-1\right)^{2}}$. Again, the public test is equivalent to the private one.

Q.E.D. 
Proposition B.2 There exists a critical value $\tilde{V}\left(q_{0}\right) \equiv \frac{1-q_{0}\left(2 q_{0}-1\right)^{2}}{4\left(1-q_{0}\right)\left(2 q_{0}-1\right)^{2}}$ such that the lobby invests in a public test if and only if $\frac{k_{p}}{\Delta}>\tilde{V}\left(q_{0}\right)$. Moreover, when $M \neq\{b\}$, a positive amount of political pressure is exerted.

Proof: In the proof of Proposition B.1 we have already shown that for $\frac{k_{p}}{\Delta} \leq$ $\frac{1}{2\left(2 q_{0}-1\right)^{2}}$ no information is bought. We analyze now the remaining interval. Computing the first order condition of the problem $\max _{x} E \Pi_{L}^{P U}(x)$ and substituting $E \Pi_{L}\left(q_{x}=1\right)=V_{A}+\frac{\Delta^{2}}{4 k_{p}}$ and $E \Pi_{L}\left(q_{x}=q_{0}\right)=V_{A}+\frac{\Delta^{2}}{4 k_{p}\left(2 q_{0}-1\right)^{2}}$, allows to check that $x^{*}>0 \Leftrightarrow 1-q_{0}-\frac{\Delta}{4 k_{p}}\left(\frac{1}{\left(2 q_{0}-1\right)^{2}}-q_{0}\right)>0 \Leftrightarrow \frac{k_{p}}{\Delta}>\tilde{V}\left(q_{0}\right)$. It remains to verify that $\frac{1-q_{0}\left(2 q_{0}-1\right)^{2}}{4\left(1-q_{0}\right)\left(2 q_{0}-1\right)^{2}}>\frac{1}{2\left(2 q_{0}-1\right)^{2}}$, which is true. Q.E.D.

Why is there no informational activity for $\frac{k_{p}}{\Delta}<\tilde{V}\left(q_{0}\right)$ ? $\frac{\partial^{2} E \Pi_{L}(x)}{\partial x \partial k_{p}}<0$ up to the threshold value of $\frac{\sqrt{q_{0}}}{2\left(2 q_{0}-1\right)}$. The pressure activity deters informational lobbying. This value lies in the second interval defined by Lemma B.2. For higher costs $\frac{k_{p}}{\Delta}$ the marginal benefit from providing information is increasing in the costs of exerting pressure. Increasing the costs of pressure further sets the stage for informational lobbying and $x^{*}>0$ when $\frac{k_{p}}{\Delta}>\tilde{V}\left(q_{0}\right)$.

Comparing the thresholds that determine the use of informational lobbying, $\frac{q_{0}}{\left(2 q_{0}-1\right)^{2} R^{2}}$ for Section 4.1, and $\tilde{V}\left(q_{0}\right)$, we see that the latter is smaller than the former if

$$
R \leq \sqrt{\frac{4\left(1-q_{0}\right) q_{0}}{1-q_{0}\left(2 q_{0}-1\right)^{2}}}
$$

This inequality holds for almost all the parameter space. In particular, if $R \leq$ $\frac{2}{\sqrt{5}} \simeq 0.895$, then it holds for every $q_{0} \in\left(\frac{1}{2}, 1\right)$. The only situation in which this inequality does not hold is if both $R$ and $q_{0}$ are very high. For example, combinations of $\left(R, q_{0}\right)$ such that $q_{0}>0.9$ and simultaneously $R>0.92$ violate the condition. Therefore, we conclude that the lobby has more incentives to use informational lobbying when he is uncertain about the payoffs of the politician than in the benchmark case (Subsection 4.1). ${ }^{44}$

$\overline{44}$ The same conclusion obtains taking as a reference value for $R$, the lobby's expectation $E(R)=\frac{1}{2}$. Comparing the threshold for the use of informational lobbying of Section 4.1 for $R=\frac{1}{2}$, with the one when $R$ is unknown, it is straightforward to check that the latter is smaller. 